\title{
Role of Projections between Piriform Cortex and Orbitofrontal Cortex in Relapse to Fentanyl Seeking after Palatable Food Choice-Induced Voluntary Abstinence
}

\author{
DDavid J. Reiner, ${ }^{1,2}$ Olivia M. Lofaro, ${ }^{1}$ Sarah V. Applebey, ${ }^{1}$ Hannah Korah, ${ }^{1}$ Marco Venniro, ${ }^{1}$ Carlo Cifani, ${ }^{1}$ \\ Jennifer M. Bossert, ${ }^{1}$ and ${ }^{D}$ Yavin Shaham ${ }^{1}$ \\ ${ }^{1}$ Behavioral Neuroscience Research Branch, Intramural Research Program, NIDA NIH, Baltimore, Maryland, and 2Postdoctoral Research Associate \\ Training Fellow, National Institute of General Medical Sciences, Bethesda, Maryland
}

\begin{abstract}
We recently developed a rat model of relapse to drug seeking after food choice-induced voluntary abstinence. Here, we used this model to study the role of the orbitofrontal cortex $(\mathrm{OFC})$ and its afferent projections in relapse to fentanyl seeking. We trained male and female rats to self-administer palatable food pellets for $6 \mathrm{~d}(6 \mathrm{~h} / \mathrm{d})$ and intravenous fentanyl $(2.5 \mu \mathrm{g} / \mathrm{kg} /$ infusion $)$ for $12 \mathrm{~d}(6 \mathrm{~h} / \mathrm{d})$. We assessed relapse to fentanyl seeking after 13-14 voluntary abstinence days, achieved through a discrete choice procedure between fentanyl infusions and palatable food ( 20 trials/d). In both sexes, relapse after food choice-induced abstinence was associated with increased expression of the activity marker Fos in the OFC. Pharmacological inactivation of the OFC with muscimol plus baclofen $(50+50 \mathrm{ng} / \mathrm{side})$ decreased relapse to fentanyl seeking. We then determined projection-specific activation of OFC afferents during the relapse test by using Fos plus the retrograde tracer cholera toxin $\mathrm{B}$ (injected into the $\mathrm{OFC}$ ). Relapse to fentanyl seeking was associated with increased Fos expression in the piriform cortex (Pir) neurons projecting to the OFC, but not in projections from the basolateral amygdala and thalamus. Pharmacological inactivation of the Pir with muscimol plus baclofen decreased relapse to fentanyl seeking after voluntary abstinence. Next, we used an anatomical disconnection procedure to determine whether projections between the Pir and OFC are critical for relapse to fentanyl seeking. Unilateral muscimol plus baclofen injections into the Pir in one hemisphere plus unilateral muscimol plus baclofen injections into the OFC in the contralateral, but not ipsilateral, hemisphere decreased relapse. Our results identify Pir-OFC projections as a new motivation-related pathway critical to relapse to opioid seeking after voluntary abstinence.
\end{abstract}

Key words: addiction; anterior insular cortex; disconnection; opioid; orbitofrontal cortex; self-administration

Significance Statement

There are few preclinical studies of fentanyl relapse, and these studies have used experimenter-imposed extinction or forced abstinence procedures. In humans, however, abstinence is often voluntary, with drug available in the drug environment but forgone in favor of nondrug alternative reinforcers. We recently developed a rat model of drug relapse after palatable food choice-induced voluntary abstinence. Here, we used classical pharmacology, immunohistochemistry, and retrograde tracing to demonstrate a critical role of the piriform and orbitofrontal cortices in relapse to opioid seeking after voluntary abstinence.

\section{Introduction}

A main feature of drug addiction is high rate of relapse during abstinence (Hunt et al., 1971; Sinha, 2011). This feature of human addiction has been traditionally modeled in laboratory ani-

Received Nov. 9, 2019; revised Dec. 26, 2019; accepted Jan. 31, 2020.

Author contributions: D.J.R., M.V., and Y.S. designed research; D.J.R., O.M.L., S.V.A., H.K., C.C., and J.M.B. performed research; D.J.R., 0.M.L., and S.V.A. analyzed data; D.J.R., 0.M.L., S.V.A., and Y.S. wrote the paper.

The research was supported by the Intramural Research Program of NIDA, a National Institute of General Medical Sciences Postdoctoral Research Associate grant (1F12GM128603) to D.J.R., and an National Alliance for Research on Schizophrenia \& Depression Distinguished Investigator Grant Award to Y.S. The authors would like to thank Rajtarun Madangopal, Soham Ghoshal, Trinity Russell, Angélica Minier-Toribio, and Jennifer Hoots for technical assistance with experiments.

The authors declare no competing financial interests. mals using extinction-reinstatement (Shalev et al., 2002; Kalivas and McFarland, 2003) or home cage forced abstinence (Venniro et al., 2016). However, from a human relapse perspective, a limitation of these procedures is that the abstinence period is experimenter imposed, whereas in humans abstinence is often voluntary due to either adverse consequences of drug use or availability of competing nondrug reinforcers (Epstein and Preston, 2003; Katz and Higgins, 2003).

Correspondence should be addressed David J. Reiner at david.reiner@nih.gov or Yavin Shaham at yavin.shaham@nih.gov.

https://doi.org/10.1523/JNEUROSCI.2693-19.2020

Copyright $\odot 2020$ the authors 
Based on these considerations, we recently developed a rat model of relapse after voluntary abstinence, achieved by providing rats with a history of drug self-administration mutually exclusive choices between high-carbohydrate palatable food and drug (Caprioli et al., 2015; Venniro et al., 2017b). Our choice procedure was inspired by studies showing that rats strongly prefer saccharin or sucrose solutions over cocaine or heroin (Ahmed et al., 2013). Using this model, we and others demonstrated a role of dorsomedial striatum, nucleus accumbens core, ventral anterior insular cortex (AIV), central amygdala (CeA), and AIV-to-CeA projections in relapse to methamphetamine seeking (Caprioli et al., 2017; Venniro et al., 2017a; Rossi et al., 2020). In contrast, the brain mechanisms of relapse to opioid seeking after voluntary abstinence are unknown.

The goal of our study was twofold. We first determined whether food choice-induced voluntary abstinence from heroin, and subsequent relapse when the food is removed (Venniro et al., 2017b), generalizes to the potent synthetic opioid fentanyl (Jaffe, 1990). The second goal was to investigate circuits of relapse to fentanyl seeking after food choice-induced abstinence. We studied orbitofrontal cortex (OFC) and its afferent projections because human studies showed that craving induced by heroin cues is associated with increased activity in the OFC (Sell et al., 2000; Langleben et al., 2008). In rats, relapse to heroin seeking after forced abstinence is associated with increased expression of Fos and other immediate early genes in the OFC (Koya et al., 2006; Kuntz et al., 2008; Fanous et al., 2012). Additionally, muscimol plus baclofen (GABAa and GABAb receptor agonists) inactivation of OFC or selective inactivation of Fos-expressing neurons, using the Daun02 inactivation procedure (Cruz et al., 2013), decreases relapse to heroin seeking after forced abstinence (Fanous et al., 2012). Inhibition of OFC neuronal activity or inhibition of OFC projections to basolateral amygdala (BLA) decreases cueinduced and context-induced reinstatement of cocaine seeking after extinction (Fuchs et al., 2004; Lasseter et al., 2009, 2011, 2014; Arguello et al., 2017). Finally, in vivo electrophysiology studies showed that cocaine or heroin self-administration impairs OFC-mediated decision-making processes (Jentsch et al., 2002; Torregrossa et al., 2008; Lucantonio et al., 2012, 2015), and OFC activity is associated with choosing cocaine or heroin versus food in the discrete-trial choice procedure (Guillem and Ahmed, 2018; Guillem et al., 2018).

Here, we showed that rats strongly prefer palatable food over intravenous fentanyl and "relapsed" to fentanyl seeking when the palatable food was removed. Relapse to fentanyl seeking was associated with increased Fos expression in the lateral and ventral OFC (IOFC, vOFC). Fos expression data are correlational and may reflect either the cause or consequence of lever pressing during the relapse tests. Therefore, we next used muscimol plus baclofen inactivation (McFarland and Kalivas, 2001) to demonstrate a causal role of the OFC in relapse to fentanyl seeking. We then combined cholera toxin subunit B (CTb; Luppi et al., 1990) retrograde tracing (injected into the $\mathrm{OFC}$ ) with Fos measurement in OFC afferent projections to determine relapse-associated, projection-specific activation (Marchant et al., 2009, 2014; Mahler and Aston-Jones, 2012). Surprisingly, relapse to fentanyl seeking was selectively associated with increased Fos expression of piriform cortex (Pir) neurons projecting to the OFC, but not other projections. In follow-up studies, we showed that muscimol plus baclofen inactivation of Pir or anatomical disconnection of projections between the Pir and OFC decreased relapse to fentanyl seeking.

\section{Materials and Methods}

\section{Subjects}

We used 132 male and 133 female Sprague Dawley rats (body weight at the time of intravenous surgery: males, 285-340 g; females, 195-225 g; Charles River). The rats were $\sim 8-10$ weeks of age at the time of intravenous surgery. We housed the rats two per cage for 1-3 weeks and then individually after surgery. We maintained the rats under a reverse $12 / 12$ $\mathrm{h}$ light/dark cycle (lights off at 8:00 A.M.) with food and water available ad libitum. We performed the experiments in accordance with the $\mathrm{Na}$ tional Institutes of Health Guide for the Care and Use of Laboratory Animals (eighth edition), under protocols approved by the Animal Care and Use Committee of NIDA Intramural Research Program. We excluded 86 rats due to catheter failure $(n=6)$, cannula misplacement $(n=$ 49), CTb injection misplacement $(n=15)$, illness $(n=14)$, or statistical outliers $[n=2,>3$ SDs during the relapse tests in experiment (exp.) 2].

\section{Drugs}

We received fentanyl citrate (fentanyl) from the NIDA pharmacy and dissolved it in sterile saline. We chose a unit dose of $2.5 \mu \mathrm{g} / \mathrm{kg} /$ infusion for self-administration training based on pilot and previous studies (Wade et al., 2015). In Exp. 2-3 and 5-6, we dissolved muscimol plus baclofen (Tocris Bioscience) in sterile saline and injected it intracranially at a dose of $50+50 \mathrm{ng}$ in $0.5 \mu \mathrm{l} /$ side (Stopper and Floresco, 2014; Venniro et al., 2017a).

\section{Intravenous surgery}

We anesthetized the rats with isoflurane gas (5\% induction; $2-3 \%$ maintenance; Butler Schein) and inserted Silastic (VWR) catheters into the jugular vein, as previously described (Venniro et al., 2017a,b). We injected the rats with ketoprofen $(2.5 \mathrm{mg} / \mathrm{kg}$, s.c.; Butler Schein) $1 \mathrm{~h}$ after surgery and the following day to relieve pain and inflammation. We allowed the rats to recover for 5-7 d before food self-administration training. During the recovery and all experimental phases, we flushed the catheters every $24-48 \mathrm{~h}$ with gentamicin $(4.25 \mathrm{mg} / \mathrm{ml}$; APP Pharmaceuticals) dissolved in sterile saline. If we suspected catheter failure during training, we tested patency with the short-acting barbiturate anesthetic Brevital (methohexital sodium, Butler Schein; $10 \mathrm{mg} / \mathrm{ml}$ in sterile saline, $0.1-0.2 \mathrm{ml}$ injection volume, i.v.), and if not patent, we catheterized the left jugular vein or eliminated the rat from the study.

\section{Intracranial surgery}

Following the last day of self-administration, we anesthetized the rats and, using a stereotaxic instrument (Kopf), implanted guide cannulas (23 gauge; Plastics One) $1 \mathrm{~mm}$ above the lOFC, vOFC, AIV, or Pir. We set the nose bar at $-3.3 \mathrm{~mm}$ and used the following coordinates from bregma: lOFC: anteroposterior (AP), $+3.4 \mathrm{~mm}$; mediolateral (ML), \pm 3.5 $\mathrm{mm}$ ( $10^{\circ}$ angle lateral to midline); dorsoventral (DV), $-4.0 \mathrm{~mm}$; vOFC: $\mathrm{AP},+3.4 \mathrm{~mm}$; $\mathrm{ML}, \pm 2.8 \mathrm{~mm}\left(10^{\circ}\right.$ angle lateral to midline); $\mathrm{DV},-4.2$ $\mathrm{mm}$; AIV: AP, $+2.8 \mathrm{~mm}$; ML, $\pm 4.9 \mathrm{~mm}\left(10^{\circ}\right.$ angle $)$; DV,$-4.2 \mathrm{~mm}$; Pir: $\mathrm{AP},+3.4 \mathrm{~mm}$; ML, $\pm 3.9 \mathrm{~mm}\left(10^{\circ}\right.$ angle lateral to midline $)$; $\mathrm{DV},-6.2$ $\mathrm{mm}$. For the disconnection study (exp. 6), we used the same Pir coordinates as above but targeted both $1 \mathrm{OFC}$ and $\mathrm{vOFC}$ with the following coordinates: contralateral to Pir: AP, $+3.4 \mathrm{~mm}$; ML, $\pm 3.1 \mathrm{~mm}\left(10^{\circ}\right.$ angle lateral to midline); $\mathrm{DV},-3.9 \mathrm{~mm}$; ipsilateral to Pir: $\mathrm{AP},+3.4 \mathrm{~mm}$; ML, $\pm 1.8 \mathrm{~mm}\left(5^{\circ}\right.$ angle medial to midline $) ; \mathrm{DV},-4.2 \mathrm{~mm}$. We counterbalanced the location of the cannulas into either the left or right hemisphere in the Pir and ipsilateral or contralateral OFC. We anchored the cannulas to the skull with jeweler's screws and dental cement. We used the above coordinates based on pilot and previous studies (Fanous et al., 2012; Li et al., 2015b; Venniro et al., 2017a).

\section{Intracranial injections}

We dissolved muscimol plus baclofen (Tocris Bioscience) in sterile saline and injected the drug $15 \mathrm{~min}$ before starting the relapse test sessions. The doses of muscimol plus baclofen $(50+50 \mathrm{ng}$ in $0.5 \mu \mathrm{l} / \mathrm{side})$ are based on previous studies (Stopper and Floresco, 2014; Venniro et al., 2017a; Pelloux et al., 2018). We injected vehicle (saline) or drug at a rate of 0.5 $\mu \mathrm{l} / \mathrm{min}$ and left the injectors (which extend $1.0 \mathrm{~mm}$ below the tips of the guide cannulas) in place for an additional minute to allow diffusion. We connected the syringe pump (Harvard Apparatus) to $10 \mu$ l Hamilton 
syringes attached to the 30 -gauge injectors via polyethylene-50 tubing. We habituated rats to the injection procedure for $3 \mathrm{~d}$ before testing. After testing, we extracted the rats' brains and stored them in $10 \%$ formalin. We sectioned the rat brains (50 $\mu \mathrm{m}$ sections) using a Leica cryostat and stained the sections with cresyl violet. Finally, we verified cannula placements under a light microscope.

\section{CTb injection into OFC}

After self-administration training, we injected CTb (List Biological Laboratories) into the OFC. We injected $30 \mathrm{nl}$ of $1 \%$ CTb unilaterally into the OFC over $5 \mathrm{~min}$, with the needle left in place for an additional $5 \mathrm{~min}$ (Mahler and Aston-Jones, 2012; Marchant et al., 2014, 2016; Venniro et al., 2017a). We counterbalanced injections into either the left or right hemisphere and used a $1.0 \mu \mathrm{l}, 32$-gauge Neuros syringe (Hamilton) attached to UltraMicroPump with a SYS-Micro4 Controller (World Precision Instruments). The coordinates for the $\mathrm{OFC}$ were $\mathrm{AP},+3.4 \mathrm{~mm}$; $\mathrm{ML}, \pm 3.1 \mathrm{~mm}\left(10^{\circ}\right.$ angle lateral to midline); $\mathrm{DV},-4.9 \mathrm{~mm}$. These coordinates are based on pilot studies in which the CTb injection encompasses both lateral and ventral OFC.

\section{Immunohistochemistry}

Immediately following the relapse test (exp. 1), we anesthetized the rats with isoflurane and perfused them transcardially with $\sim 200 \mathrm{ml}$ of $0.1 \mathrm{M}$ diethylpyrocarbonate (DEPC)-treated PBS, pH 7.4, followed by $\sim 400 \mathrm{ml}$ of $4 \%$ paraformaldehyde (PFA) in DEPC-treated PBS. We removed the brains and postfixed them in $4 \%$ PFA for $2 \mathrm{~h}$ before transferring them to $30 \%$ sucrose in PBS for $48 \mathrm{~h}$ at $4^{\circ} \mathrm{C}$. We froze the brains in dry ice and cut coronal sections $(40 \mu \mathrm{m})$ of the different brain areas using a Leica cryostat. We collected the sections in PBS and stored them at $4^{\circ} \mathrm{C}$ until further processing. We followed this same procedure for exp. 4, except that the rats were transcardially perfused with $\sim 200 \mathrm{ml}$ of $0.1 \mathrm{M}$ PBS, pH 7.4, followed by $\sim 400 \mathrm{ml}$ of $4 \%$ PFA in PBS.

Fos labeling (exp. 1). We rinsed free-floating sections $(3 \times 8 \mathrm{~min})$ in PBS, incubated them for $1 \mathrm{~h}$ in $4 \%$ bovine serum albumin (BSA) in PBS with $0.5 \%$ Triton X-100 (PBS-Tx), and incubated them for $48 \mathrm{~h}$ at $4{ }^{\circ} \mathrm{C}$ with rabbit anti-c-Fos primary antibody (1:1000; Phospho-c-Fos, 5348S, RRID: AB_10557109, Cell Signaling Technology) diluted in 4\% BSA in PBS-Tx. We then rinsed the sections in PBS and incubated them for $4 \mathrm{~h}$ with donkey anti-rabbit Alexa Fluor 594 secondary antibody (1:500; 711585-152, RRID: AB_2340621, Jackson ImmunoResearch) diluted in 4\% BSA in $0.5 \%$ PBS-Tx. We rinsed the sections again in PBS, mounted them onto gelatin-coated slides, allowed them to air dry, and coverslipped them with vectashield Hard Set Mounting Medium with DAPI (H-1500, RRID: AB_2336788, Vector Laboratories).

$C T b$ injection site verification (exp. 4). We selected a one-in-four series of $40 \mu \mathrm{m}$ sections from the OFC of each rat to determine CTb injection sites. We repeatedly rinsed free-floating sections in PBS $(3 \times 10 \mathrm{~min})$ and incubated them for $1 \mathrm{~h}$ in $0.5 \%$ PBS-Tx with $10 \%$ normal horse serum (NHS). We then incubated sections overnight at $4^{\circ} \mathrm{C}$ in goat anti-CTb primary antibody (1:2000; 703, RRID: AB_10013220, List Biological Laboratories) diluted in $0.5 \%$ PBS-Tx with $2 \%$ NHS. We rinsed the sections with PBS and incubated them for $2 \mathrm{~h}$ in biotinylated horse anti-goat secondary antibody (1:600; BA-9500, RRID: AB_2336123, Vector Laboratories) diluted in $0.5 \%$ PBS-Tx with $2 \%$ NHS. We rinsed the sections again in PBS and incubated them in avidin-biotin-peroxidase complex (ABC Standard kit, PK-6100, RRID: AB_2336819, Vector Laboratories) in $0.5 \%$ PBS-Tx for $1 \mathrm{~h}$. We then rinsed the sections in PBS, developed them in 3,3'-diaminobenzidine in $0.3 \%$ hydrogen peroxide, rinsed them in PBS for $30 \mathrm{~min}$, mounted them onto gelatin-coated slides, and air dried them. We dehydrated the slides through a graded series of alcohol concentrations $(30,60,90,95,100 \%$ ethanol), cleaned the slides with Citra Solv (Fisher Scientific), and coverslipped them with Permount (Fisher Scientific). We only included rats in which the CTb injection site was restricted to the OFC.

Fos and CTb double labeling (exp. 4). We processed a one-in-four series of Pir, BLA, and thalamus for immunohistochemical detection of Fos and $\mathrm{CTb}$. We rinsed free-floating sections $(3 \times 10 \mathrm{~min})$ and then incubated them in $10 \%$ NHS with $0.5 \%$ PBS-Tx for $2 \mathrm{~h}$. We then incubated the sections for $48 \mathrm{~h}$ at $4^{\circ} \mathrm{C}$ in $0.5 \%$ PBS-Tx containing $2 \%$ NHS with rabbit anti-c-Fos primary antibody (1:1000; Phospho-c-Fos, 5348S, RRID: AB_10557109, Cell Signaling Technology) and goat anti-CTb primary antibody (1:1000; CTb 703, RRID: AB_10013220, List Biological Laboratories). We rinsed the sections in PBS and incubated them for $4 \mathrm{~h}$ in $0.5 \%$ PBS-Tx containing 2\% NHS and donkey anti-rabbit Alexa Fluor 594 (1:500; 711-585-152, RRID: AB_2340621, Jackson ImmunoResearch,) and donkey anti-goat Alexa Fluor 488 (1:500; 705-546-147, RRID: AB_2340430, Jackson ImmunoResearch). We rinsed the sections in PBS $(3 \times 10 \mathrm{~min})$ and mounted them onto gelatin-coated slides, partially dried, and coverslipped the sections with vectashield Hard Set Mounting Medium with DAPI (H-1500, RRID: AB_2336788, Vector Laboratories).

\section{Self-administration apparatus}

We trained rats to self-administer food and fentanyl in standard selfadministration chambers (Med Associates) as described previously (Caprioli et al., 2015, 2017; Venniro et al., 2017b). We equipped each self-administration chamber with two operant panels with three levers located 7-8 cm above the stainless-steel grid floor. We equipped the right panel of the chamber with a discriminative cue (white house light; ENV$215 \mathrm{M}$, Med Associates) that signaled the insertion and subsequent availability of the food-paired active (retractable) lever. We equipped the left panel of the chamber with a discriminative cue (red light; ENV-221M, red lens, Med Associates) that signaled the insertion and subsequent availability of the fentanyl-paired active (retractable) lever. We also equipped the right wall with an inactive (stationary) lever that had no reinforced consequences. We placed a bottle of water and a food hopper with standard laboratory chow on the chamber's transparent polycarbonate door.

\section{General procedure}

The experiments generally consisted of three phases: food selfadministration (6 d) and fentanyl self-administration (12 d), voluntary abstinence choice sessions (10-12 sessions over 13-14 d), followed by relapse and reacquisition tests. We provide details of the phases here.

Food pellet self-administration. Before the first self-administration training session, we gave the rats a $1 \mathrm{~h}$ magazine training session, which began with the presentation of the white house light, followed by the noncontingent delivery of five pellets every $5 \mathrm{~min}$. We used $45 \mathrm{mg}$ "preferred" or palatable food pellets described in our previous studies $(12.7 \%$ fat, $66.7 \%$ carbohydrate, and $20.6 \%$ protein; TestDiet $45 \mathrm{mg}$ pellet no. 1811155; Cifani et al., 2012; Pickens et al., 2012; Calu et al., 2014). We then trained rats to lever press for food during six $1 \mathrm{~h}$ sessions that were separated by $10 \mathrm{~min}$ for six consecutive days. The sessions began with the presentation of the white house light, followed $10 \mathrm{~s}$ later by the insertion of the food-paired active lever (right panel). The white house light remained on for the duration of the session and served as a discriminative cue for the palatable food. We trained the rats under a fixed-ratio-1 (FR1) reinforcement schedule, where one lever press resulted in the delivery of five $45 \mathrm{mg}$ palatable food pellets and the presentation of a $20 \mathrm{~s}$ discrete tone cue (ENV-223AM, Med Associates), during which additional lever presses were not reinforced but still recorded. At the end of each $1 \mathrm{~h}$ session, the white house light was turned off and the active lever was retracted. To match the number of discrete cue presentations to that of fentanyl (see below), we limited the number of food-reinforced deliveries to $12 / \mathrm{h}$.

Fentanyl self-administration. We trained rats to self-administer fentanyl during six $1 \mathrm{~h}$ daily sessions that were separated by $10 \mathrm{~min}$ for $12 \mathrm{~d}$. Fentanyl was infused at a dose of $2.5 \mu \mathrm{g} / \mathrm{kg} /$ infusion over $3.5 \mathrm{~s}(0.1$ $\mathrm{ml} /$ infusion). Sessions began with presentation of the red house light for $10 \mathrm{~s}$ followed by the insertion of the fentanyl-paired active lever; the red house light remained on for the duration of the session and served as a discriminative cue for fentanyl availability. We trained the rats under an FR1 reinforcement schedule, where one lever press resulted in the delivery of a drug infusion paired with the $20 \mathrm{~s}$ discrete white light cue above the fentanyl-paired active lever (ENV-221M, white lens, Med Associates). At the end of each $1 \mathrm{~h}$ session, the red light was turned off and the active lever was retracted. To prevent overdose and decrease selfinjurious biting and excessive grooming, we limited the number of infu- 
sions to $12 / \mathrm{h}$. In addition, to decrease self-injurious biting, we provided Nylabones (Bio-Serv) in the home cage and in the operant chamber beginning with the first day of food self-administration and removed the Nylabones from the operant chamber for choice sessions and relapse and reacquisition tests.

Discrete-trial choice procedure. We conducted the discrete choice sessions using the same parameters (dose of fentanyl, number of palatable food pellets per reinforcer delivery, stimuli associated with the two retractable levers) used during the training phase. We allowed the rats to choose between the fentanyl-paired and the palatable food-paired lever in a discrete-trial choice procedure. We divided each $3 \mathrm{~h}$ choice session into 20 discrete trials that were separated by $9 \mathrm{~min}$, as previously described (Caprioli et al., 2015; Venniro et al., 2017a, b). Each trial began with the presentation of both discriminative cues previously associated with palatable food or fentanyl, followed $10 \mathrm{~s}$ later by the insertion of both the palatable food-paired and fentanyl-paired levers. Rats could then select one of the two levers. If the rats responded within $6 \mathrm{~min}$, the reinforcer associated with the selected lever was delivered. Each reinforcer delivery was signaled by the fentanyl-associated or food-associated cue (white cue light or tone, respectively), retraction of both levers, and shutdown of the food and fentanyl discriminative cues. Thus, on a given trial, the rat could earn the drug or food reinforcer, but not both. If a rat failed to respond on either active lever within $6 \mathrm{~min}$, both levers were retracted and their related discriminative cues were shut down with no reinforcer delivery until onset of the next trial (Caprioli et al., 2015). We incorporated three choice sessions during fentanyl self-administration training (each choice session occurred after $3 \mathrm{~d}$ of fentanyl self-administration) to determine the time course of the choice behavior during training.

Voluntary abstinence. After completion of the training phase, we allowed the rats to choose between the fentanyl-paired lever (delivering one infusion) and palatable food-paired lever (delivering five pellets) during 20 discrete choice trials for $10-12$ daily sessions, as described earlier. For exp. 2-6, we started the voluntary abstinence choice sessions on abstinence day 5 .

Relapse and reacquisition tests. The relapse test in the presence of the fentanyl-associated cues consisted of a single 30-180 min session (see specific experiments) on abstinence day 1 (exp. 1), 14 (exp. 1), or 15 (exp. $2-6$ ). The sessions began with the presentation of the red discriminative cue light, followed 10 s later by the insertion of the fentanyl-paired active lever; the red light remained on for the duration of the session. Active lever presses during testing resulted in contingent presentations of the light cue previously paired with drug infusions, but not an infusion of fentanyl. For the $180 \mathrm{~min}$ relapse test sessions, there was a $10 \mathrm{~min}$ timeout at the 60 and 120 min time points, during which the fentanyl-paired active lever retracted, and the fentanyl-associated discriminative cue light turned off (except where noted). Based on our previous studies (Bossert et al., 2011; Li et al., 2015a; Caprioli et al., 2017; Venniro et al., 2017a) and the time course of Fos induction (Morgan and Curran, 1991), the relapse tests were 60 or $90 \mathrm{~min}$ in experiments in which we measured Fos protein expression. In experiments in which we tested the effect of muscimol plus baclofen on relapse, the test duration was $3 \mathrm{~h}$. Either 1 or $2 \mathrm{~d}$ after the relapse test, we tested the rats on reacquisition of fentanyl self-administration using the same parameters as the fentanyl self-administration training. In exp. 6 , we tested reacquisition 1 week after the relapse test.

\section{Exp. 1: Effect of relapse to fentanyl seeking after voluntary}

abstinence on Fos expression $(\mathrm{n}=42)$

The first goal of exp. 1 was to determine whether the food choice-induced voluntary abstinence model generalizes to fentanyl in male $(n=22)$ and female $(n=20)$ rats. The experiment consisted of three phases: food and fentanyl self-administration training phase (3 weeks), choice-induced voluntary abstinence phase $(13 \mathrm{~d})$, and relapse tests. In our previous study, we found that food choice-induced abstinence prevents the emergence of the time-dependent increases in heroin seeking that occur after home cage forced abstinence (incubation of heroin craving; Venniro et al., 2017b). Thus, in exp. 1, we tested whether this effect generalizes to fentanyl by testing the rats for relapse on abstinence day 1 (30 min ses- sion) and after food choice-induced abstinence (day 14, 60 min session). We did not observe time-dependent increases in fentanyl seeking in the comparison of the $30 \mathrm{~min}$ day 1 test with the first $30 \mathrm{~min}$ of the day 14 test (abstinence day 1: $48 \pm 7$ for males, $41 \pm 6$ for females; abstinence day 14: $44 \pm 4$ for males, $47 \pm 6$ for females; data are the mean \pm SEM). Based on these data, in subsequent experiments we omitted the day 1 testing and only tested the rats after food choice-induced abstinence. Additionally, because we did not observe any sex differences in exp. 1, we used an equal number of male and female rats in the different groups in exp. 2-6, which were not powered to detect sex differences.

A second goal of exp. 1 was to determine whether relapse to fentanyl seeking after voluntary abstinence is associated with increased Fos expression in the OFC after the $60 \mathrm{~min}$ day 14 relapse test. We also measured Fos in the adjacent anterior insular cortex dorsal (AID) and AIV subregions, because recent studies demonstrated a role of this region in reinstatement of nicotine and cocaine seeking after extinction and relapse to methamphetamine after food choice-induced abstinence (Cosme et al., 2015; Pushparaj et al., 2015; Rotge et al., 2017; Venniro et al., 2017a).

We used a subset of rats in two groups ( $n=7$ /group) in an experimental design that included the between-subjects factor of test condition (no test, test). We matched the groups in exp. 1 (and in all other experiments) for fentanyl intake during the training phase. On abstinence day 14, all rats went through the relapse test, and only rats from the test group were perfused immediately after the relapse test. Rats from the no test group were perfused the following day (Fig. 1).

\section{Exp. 2: Effect of OFC inactivation on relapse to fentanyl seeking} after voluntary abstinence $(\mathrm{n}=38)$

In exp. 1, we found that relapse to fentanyl seeking was associated with strong increase in Fos expression in the lOFC and vOFC. Therefore, the goal of exp. 2 was to determine whether these OFC subregions play causal roles in relapse to fentanyl seeking after voluntary abstinence. The experiment consisted of three phases: food and fentanyl self-administration training phase (3 weeks), choice-induced voluntary abstinence phase (10 sessions over $14 \mathrm{~d}$ ), and relapse test and reacquisition tests. We targeted the lOFC and vOFC separately using different stereotaxic coordinates. Because we did not observe any differences between the vehicle lOFC and vehicle vOFC groups in either relapse or reacquisition, we combined the data for a total of three groups ( $n=17$ vehicle, $n=11$ lOFC muscimol plus baclofen, $n=10$ vOFC muscimol plus baclofen). Due to an experimenter error, during the relapse test for four rats, the fentanyl-paired active lever was inserted during the entire $180 \mathrm{~min}$ session with no timeouts at the 60 and $120 \mathrm{~min}$ time points (Fig. 2). These rats were included in the analyses because their data did not differ from the other rats within their treatment groups.

\section{Exp. 3: Effect of AIV inactivation on relapse to fentanyl seeking} after voluntary abstinence $(\mathrm{n}=26)$

In exp. 1, we found that relapse to fentanyl seeking was associated with a modest but significant increase in Fos expression in the AIV. The goal of exp. 3 was to determine whether this region also plays a causal role in relapse to fentanyl seeking. The experiment consisted of three phases: food and fentanyl self-administration training phase ( 3 weeks), choiceinduced voluntary abstinence phase (10 sessions over $14 \mathrm{~d})$, and relapse and reacquisition tests. We tested two groups of rats $(n=13 /$ group $)$ in an experimental design that included the between-subjects factor of drug condition (vehicle, muscimol plus baclofen; Fig. 3).

\section{Exp. 4: Effect of relapse to fentanyl seeking on Fos expression in} afferent projections to OFC $(\mathrm{n}=12)$

The goal of exp. 4 was to characterize the circuitry of relapse to fentanyl seeking after voluntary abstinence by determining whether this relapse is associated with selective activation of one or more afferent projections into the OFC. The experiment consisted of three phases: food and fentanyl self-administration training phase (3 weeks), choice-based voluntary abstinence phase (10 sessions over $14 \mathrm{~d}$ ), and relapse test. We injected CTb into the OFC $1 \mathrm{~d}$ after the last self-administration session and started the voluntary abstinence phase $4 \mathrm{~d}$ after these injections. We used two groups of rats ( $n=5-7 /$ group) in an experimental design that included 
the between-subjects factor of test condition (no test, test). On test day, we brought the rats from the no test group directly from their home cage and perfused them at the same time as the rats from the test group (Fig. 4).

Exp. 5: Effect of Pir inactivation on relapse to fentanyl seeking after voluntary abstinence $(\mathrm{n}=29)$

The goal of exp. 5 was to determine whether the Pir plays a causal role in relapse to fentanyl seeking after voluntary abstinence. The experiment consisted of three phases: food and fentanyl self-administration training phase (3 weeks), choice-induced voluntary abstinence phase ( 10 sessions over $14 \mathrm{~d}$ ), and relapse and reacquisition tests. Due to an experimenter error, on the first day of voluntary abstinence, 12 male rats received access to fentanyl self-administration for $2 \mathrm{~h}$ before the initial choice session. Data from these rats did not differ from the rest of the rats within their treatment groups and were included in subsequent analyses. We tested two groups of rats ( $n=14-15$ /group) in an experimental design that included the between-subjects factor of drug condition (vehicle, muscimol plus baclofen; Fig. 5).

Exp. 6: Effect of anatomical disconnection between Pir and OFC on relapse to fentanyl seeking $(\mathrm{n}=32)$

The goal of exp. 6 was to determine whether projections between Pir and OFC play a causal role in relapse to fentanyl seeking. For this purpose, we used an anatomical disconnection procedure, in which the role of a neuronal pathway or projection in a given behavior is then inferred when behavior is disrupted by the contralateral, but not ipsilateral, inactivation of two anatomically connected brain regions (Gaffan et al., 1993; Setlow et al., 2002). Importantly, the Pir projections to the OFC are primarily ipsilateral with minimal contralateral retrograde labeling in the Pir (Murphy and Deutch, 2018). This ipsilateral connectivity is required to properly interpret findings from anatomical disconnection studies.

The experiment consisted of three phases: food and fentanyl selfadministration training phase ( 3 weeks), choice-induced voluntary abstinence phase (10 sessions over $14 \mathrm{~d}$ ), and a relapse test. We tested four groups of rats ( $n=5-11$ /group) using a 2 (drug condition: vehicle, muscimol plus baclofen $) \times 2$ (disconnection manipulation: ipsilateral, contralateral injections) experimental design. Because we did not observe any differences in the vehicle ipsilateral and vehicle contralateral groups, we combined data from these two groups for a total of three groups ( $n=12$ vehicle, $n=9$ ipsilateral muscimol plus baclofen, $n=11$ contralateral muscimol plus baclofen). We tested a subset of rats from the contralateral condition ( $n=5 /$ group) for reacquisition of fentanyl selfadministration 1 week after the relapse test. The experimental design included the between-subjects factor of drug condition (vehicle, muscimol plus baclofen). One rat began the reacquisition session $\sim 1 \mathrm{~h}$ after receiving the injection (Fig. 6).

\section{Quantification and statistical analysis}

Image acquisition and neuronal quantification. For cannula placements and CTb injection site verification, we used a Retiga 2000R Fast 1394 (QImaging) attached to a Zeiss Axio Scope Imager Al using iVision (V.0.15 and 4.5.0, Biovision Technologies). For exp. 1, we used an EXi Aqua camera (QImaging) attached to a Zeiss Axio Scope Imager M2 using iVision (V.0.15 and 4.5.0, Biovision Technologies), and for exp. 4, we used an ORCA Flash 4.0LT (Hamamatsu Photonics) attached to a Zeiss Axio Scope Imager M2 using MicroManager (V1.4) (Edelstein et al., 2014).

Exp. 1: Fos quantification. We captured immunofluorescent images for Fos immunoreactive (IR) cells in the OFC, AIV, and AID using a $10 \times$ objective. We analyzed the sections of OFC, AIV, and AID within the bregma coordinates of +4.2 to $+2.8 \mathrm{~mm}$. For each rat, we identified Fos + cells by a fluorescent stain in the nuclei. We quantified cells in two hemispheres of two sections and computed the mean of these counts per area (i.e., each rat provides an individual data point for data analyses with data averaged from four images for each rat). We performed image-based quantification in a blind manner (inter-rater reliability for OFC, AIV, and AID counting between DJR and CC, $r=0.963, p>0.05$ ).

Exp. 4: Fos plus CTb quantification. We captured immunofluorescent images for Fos-IR and CTb-IR cells in the Pir, BLA, and thalamus using a
$10 \times$ objective. For each rat, we quantified cells in the same hemisphere as the CTb injection in the following bregma coordinates: Pir $(+4.2$ to +3.0 $\mathrm{mm})$, BLA $(-1.8$ to $-2.6 \mathrm{~mm})$, thalamus $(-1.8$ to $-3.0 \mathrm{~mm})$. For each rat, we identified $\mathrm{CTb}+$ cells by a fluorescent stain in the cytoplasm and Fos + cells by a fluorescent stain in the nuclei. We quantified cells in the hemisphere ipsilateral to the injection site in four sections and computed the mean of these counts per area (i.e., each rat provides an individual data point for data analyses with data averaged from four images for each rat). We performed image-based quantification of $\mathrm{CTb}+$, Fos + , and $\mathrm{CTb}+/$ Fos + cells in Image $(\mathrm{NIH})$ in a blind manner (inter-rater reliability between DJR and OML, $r=0.970, p>0.05$, and between DJR and $\mathrm{SG}, r=0.974, p>0.05)$.

Statistical analysis. We analyzed the data with repeated-measures or mixed-factorial ANOVAs using SPSS (version 23, IBM; GLM procedure). We followed significant main effects and interactions $(p<0.05)$ with post hoc tests (univariate ANOVAs or Fisher's PLSD). We describe the different between-subjects and within-subjects factors for the different statistical analyses in the Results section. We only report significant effects that are critical for data interpretation, as our multifactorial ANOVAs yielded multiple main and interaction effects. We indicate the results of post hoc analyses with asterisks in the figures but do not describe them in the text. For individual data of bar graphs described in Figures 1-6, see Extended Data Fig. 1-1, available at https://doi.org/10.1523/ JNEUROSCI.2693-19.2020.f1-1; Fig. 2-1, available at https://doi.org/ 10.1523/JNEUROSCI.2693-19.2020.f2-1; Fig. 3-1, available at https:// doi.org/10.1523/JNEUROSCI.2693-19.2020.f3-1; Fig. 4-1, available at https://doi.org/10.1523/JNEUROSCI.2693-19.2020.f4-1; Fig. 5-1, available at https://doi.org/10.1523/JNEUROSCI.2693-19.2020.f5-1; and Fig. 6-1, available at https://doi.org/10.1523/JNEUROSCI.2693-19.2020. f6-1. For group means and individual data of rats with cannula misplacements from exp. 2, 3, 5, and 6, see Extended Data Fig. 2-2, available at https://doi.org/10.1523/JNEUROSCI.2693-19.2020.f2-2.

\section{Results}

\section{Self-administration training and choice}

In all experiments, male and female rats reliably self-administered palatable food and fentanyl (Figs. $1 B, 2 B, 3 B, 4 B, 5 B, 6 B$ ) and strongly preferred palatable food over fentanyl in the three choice sessions during training (Figs. $1 C, 2 C, 3 C, 4 C, 5 C, 6 C$ ) and during food choice-induced voluntary abstinence (Figs. $1 D, 2 D$, $3 D, 4 D, 5 D, 6 D)$. We observed no sex differences in food or fentanyl self-administration in the different experiments. In exp. 1 , preference for palatable food was higher in males than in females during choice-induced voluntary abstinence (Fig. 1D; $\left.F_{(1,40)}=16.2, p<0.001\right)$. We did not observe additional sex differences in any of the measures in subsequent experiments and combined data from males and females in exp. 2-6.

\section{Exp. 1: Effect of relapse to fentanyl seeking after voluntary abstinence on Fos expression}

The goal of exp. 1 was to determine whether relapse to fentanyl seeking after food choice-induced voluntary abstinence was associated with activation of the OFC, as assessed by the activity marker Fos. We also measured Fos in the nearby AID and AIV. The timeline of exp. 1 is provided in Figure $1 A$.

\section{Relapse test (day 14)}

The number of lever presses on the active lever were greater than on the inactive lever during relapse to fentanyl seeking (Fig. 1E, left; Extended Data Fig. 1-1 A, available at https://doi.org/10.1523/ JNEUROSCI.2693-19.2020.f1-1 for individual data). The repeatedmeasures ANOVA for total number of lever presses included the between-subjects factor of sex and the within-subjects factor of lever (active, inactive). This analysis showed significant effects of lever $\left(F_{(1,40)}=175.1, p<0.001\right)$ but not sex $\left(F_{(1,40)}=1.2\right.$, $p=0.271)$ or an interaction between the two factors $\left(F_{(1,40)}=\right.$ 
$0.4, p=0.56)$. For the time course of lever presses (Fig. 1E, right), the repeated-measures ANOVA included the between-subjects factor of sex and the within-subjects factors of session time (20, 40, $60 \mathrm{~min})$ and lever. This analysis showed significant effects of session time $\left(F_{(2,80)}=119.1, p<0.001\right)$ and lever $\left(F_{(1,40)}=175.1, p<0.001\right)$ and an interaction between the two factors $\left(F_{(2,80)}=\right.$ $119.9, p<0.001)$. There were no significant effects of sex or interactions between sex and the other within-subjects factors $(p>0.05$; Fig. 1E).

\section{Fos expression}

We measured Fos expression after the day 14 relapse test (Fig. $1 F, G$; Extended Data Fig. 1-1 $B$, available at https://doi.org/ 10.1523/JNEUROSCI.2693-19.2020.f1-1 for individual data). This relapse was associated with a large increase in Fos expression in the lOFC and vOFC, a modest increase in the AIV, and no change in the AID. The mixed-factorial ANOVA for number of Fos + cells $/ \mathrm{mm}^{2}$ in OFC or AI subregions included the between-subjects factor of test condition (no test, test) and the within-subjects factor of brain region (lOFC, vOFC, AID, AIV). This analysis showed significant effects of test condition $\left(F_{(1,11)}=31.3, p<0.001\right)$, brain region $\left(F_{(1,11)}=34.4, p<0.001\right)$, and an interaction between the two factors $\left(F_{(1,11)}=31.0, p<0.001\right)$.

Together, relapse to fentanyl seeking was associated with increased Fos expression in the OFC and AIV.

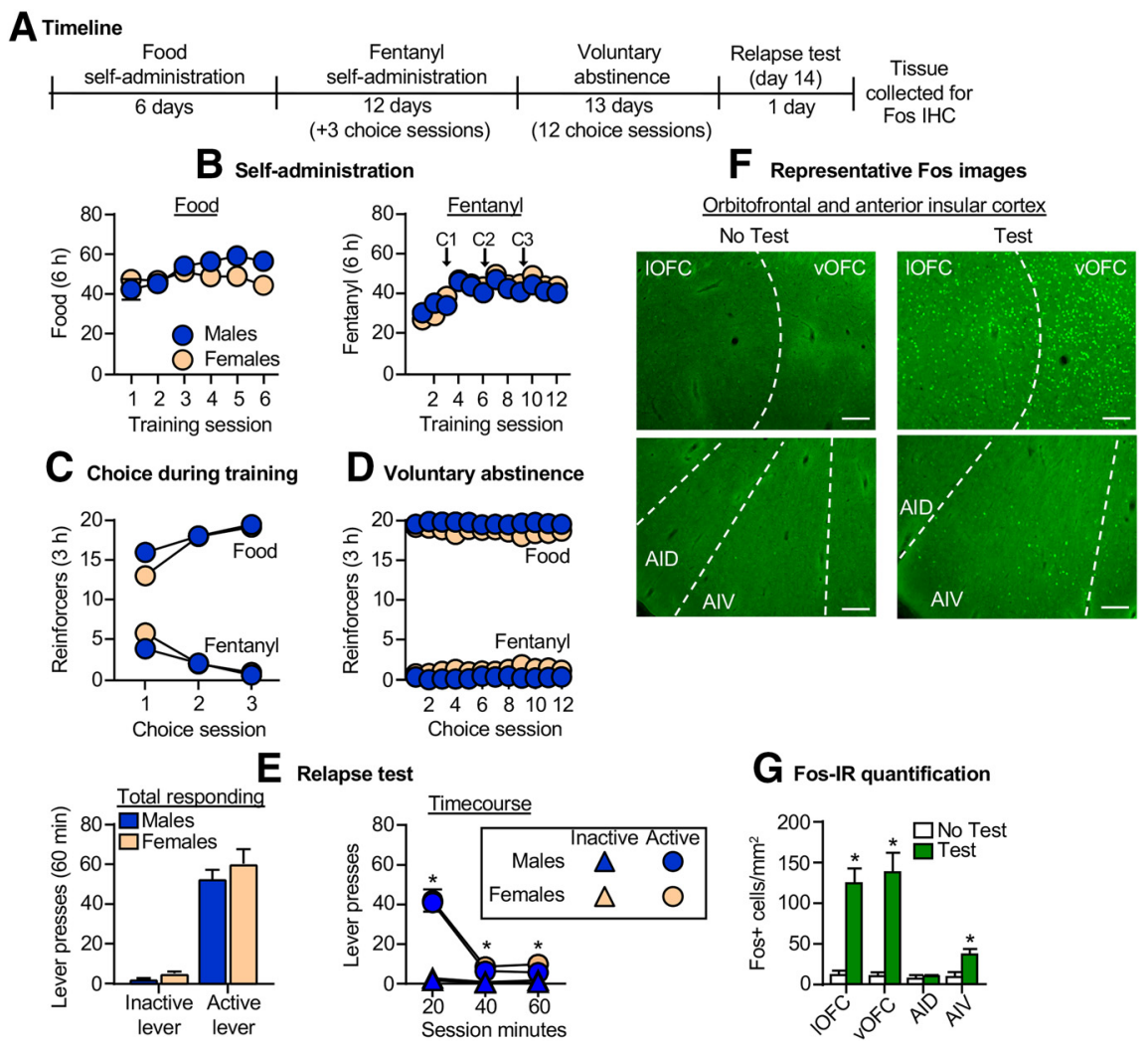

Figure 1. Effect of relapse to fentanyl seeking after voluntary abstinence on Fos expression. $A$, Timeline of exp. 1. $B$, Selfadministration: number of reinforced responses (food, 5 pellets/reinforcer delivery; fentanyl, $2.5 \mu \mathrm{g} / \mathrm{kg} /$ infusion) during the $6 \mathrm{~h}$ sessions. C, Choice during training: number of food-reinforced responses and fentanyl infusions earned during the $3 \mathrm{~h}$ choice sessions ( 20 trials/session), denoted by $C_{1}, C 2$, and $C 3$ in $\boldsymbol{B}$. D. Voluntary abstinence: number of food-reinforced responses and fentanyl infusions earned during the $3 \mathrm{~h}$ choice sessions ( 20 trials/session). $\boldsymbol{E}$, Relapse test: number of active and inactive lever presses during 60 min test session (left) and the 20 min time course (right; $n=22$ males, 20 females, between-subjects design). ${ }^{*} p<0.05$, different from the inactive lever. $\boldsymbol{F}$, Representative images of Fos + cells in orbitofrontal and anterior insular cortex, at $10 \times$ magnification. Scale bar, $100 \mu \mathrm{m}$. G, Fos-IR quantification: number of Fos + cells $\left(\right.$ counts $\left./ \mathrm{mm}^{2}\right) .{ }^{*} p<0.05$, different from the no test group ( $n=7 /$ group, between-subjects design). Data are the mean \pm SEM. For individual data, see Extended Data Figure 1-1, available at https://doi.org/10.1523/JNEUROSCI.2693-19.2020.f1-1.

\section{Exp. 2: Effect of OFC inactivation on relapse to fentanyl seeking after voluntary abstinence}

In exp. 1, we found that relapse after voluntary abstinence was associated with a large increase in Fos expression in OFC. The goal of exp. 2 was to determine a causal role of the lOFC and vOFC in this relapse. Because we did not observe any differences between vehicle injections in the two OFC subregions in either relapse or reacquisition, we combined the data for the vehicle groups. The timeline of exp. 2 is provided in Figure $2 A$.

\section{Relapse test}

Muscimol plus baclofen injections into the lOFC, but not the vOFC, significantly decreased relapse to fentanyl seeking (Fig. 2E, left; Extended Data Fig. 2-1 A, available at https:/doi.org/10.1523/ JNEUROSCI.2693-19.2020.f2-1 for individual data). The repeatedmeasures ANOVA for number of total lever presses included the between-subjects factor of drug condition (vehicle, lOFC muscimol plus baclofen, vOFC muscimol plus baclofen) and the within-subjects factor of lever. This analysis showed significant effects of drug condition $\left(F_{(2,35)}=3.3, p=0.048\right)$, lever $\left(F_{(1,35)}=\right.$ 121.7, $p<0.001)$, and a significant interaction between drug condition and lever $\left(F_{(2,35)}=3.4, p=0.042\right)$. For the time course of lever presses (Fig. 2E, right), the mixed-factorial ANOVA for number of active lever presses included the between-subjects fac- tor of drug condition and the within-subjects factor of session hour (1-3). This analysis showed significant effects of drug condition $\left(F_{(2,35)}=3.5, p=0.04\right)$ and session hour $\left(F_{(2,70)}=79.2\right.$, $p<0.001)$ but not an interaction between the two factors $\left(F_{(4,70)}\right.$ $=2.3, p=0.065)$. Additionally, there were no significant effects for inactive lever presses, which were very low $(p>0.05 ;$ Fig. $2 E)$. There was no difference in relapse responding for rats with cannula misplacements from this experiment $(p=0.37 ; n=2$ vehicle, $n=6$ muscimol plus baclofen; Extended Data Fig. 2-2, available at https://doi.org/10.1523/JNEUROSCI.2693-19.2020. f2-2).

\section{Reacquisition test}

Muscimol plus baclofen injections into either the lOFC or vOFC had no effect on reacquisition of fentanyl self-administration (Fig. 2F; Extended Data Fig. 2-1B, available at https://doi.org/ 10.1523/JNEUROSCI.2693-19.2020.f2-1 for individual data). The mixed-factorial ANOVA for number of infusions included the between-subjects factor of drug condition and the within-subjects factor of session hour (1-6). This analysis showed a significant effect of session hour $\left(F_{(5,170)}=2.9, p=\right.$ $0.016)$ but no effect of drug condition $\left(F_{(3,34)}=2.3, p=0.121\right)$ or an interaction between the two factors $\left(F_{(10,170)}=1.5, p=\right.$ $0.144)$. 


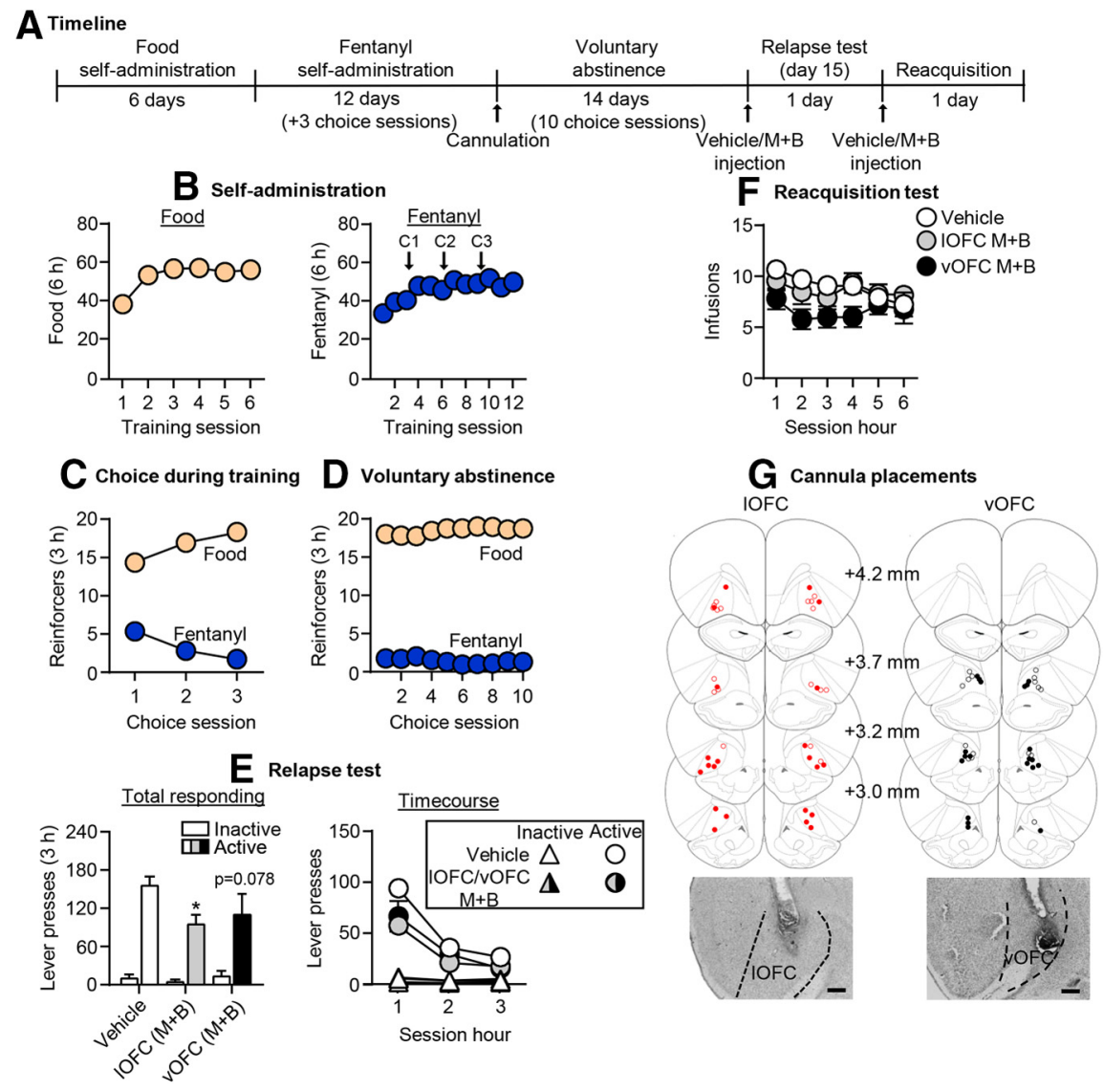

Figure 2. Effect of OFC inactivation on relapse to fentanyl seeking after voluntary abstinence. $\boldsymbol{A}$, Timeline of exp. 2. B, Selfadministration: number of reinforced responses (food, 5 pellets/reinforcer; fentanyl, $2.5 \mu \mathrm{g} / \mathrm{kg} /$ infusion) during the $6 \mathrm{~h}$ sessions. C, Choice during training: number of food-reinforced responses and fentanyl infusions earned during the $3 \mathrm{~h}$ choice sessions (20 trials/session), denoted by $C_{1}, C 2$, and $C 3$ in $\boldsymbol{B}$. D. Voluntary abstinence: number of food-reinforced responses and fentanyl infusions earned during the $3 \mathrm{~h}$ choice sessions (20 trials/session). $\boldsymbol{E}$, Relapse test: number of active and inactive lever presses during the $3 \mathrm{~h}$ test session (left) and $1 \mathrm{~h}$ time course (right) after vehicle or muscimol plus baclofen $\left(\mathrm{M}+\mathrm{B}\right.$ ) injections. ${ }^{*} p<0.05$, different from vehicle group. $\boldsymbol{F}$, Reacquisition test: number of fentanyl infusions ( $2.5 \mu \mathrm{g} / \mathrm{kg} /$ infusion) during the $1 \mathrm{~h}$ time course of the $6 \mathrm{~h}$ session after vehicle or muscimol plus baclofen injection ( $n=10-17 /$ group, between-subjects design). Data are the mean \pm SEM. G, Images showing placement of cannula into the $0 \mathrm{FC}$ at $2.5 \times$ magnification. Scale bar, $500 \mu \mathrm{m}$. Placements for lateral OFC are shown in red, and placements for ventral OFC are shown in black. Vehicle placements are shown with open circles, and muscimol plus baclofen placements are shown with closed circles. For individual data, see Extended Data Figure 2-1, available at https://doi.org/10.1523/JNEUROSCI.2693-19.2020.f2-1. For data from cannula misplacements, see Extended Data Figure 2-2, available at https://doi.org/10.1523/JNEUROSCI.2693-19.2020.f2-2. the within-subjects factor of lever. This analysis showed significant effects of drug condition $\left(F_{(1,24)}=4.3, p=0.049\right)$, lever $\left(F_{(1,24)}=66.6, p<0.001\right)$, and a significant interaction between drug condition and lever $\left(F_{(1,24)}=4.6, p=0.043\right)$. For the time course (Fig. $3 E$, right), the mixedfactorial ANOVA for number of active lever presses showed significant effects of drug condition $\left(F_{(1,24)}=4.5, p=0.045\right)$ and session hour $\left(F_{(2,48)}=44.7, p<\right.$ $0.001)$ but no interaction between the two factors $\left(F_{(1,46)}=1.7, p=0.19\right)$. A similar analysis of inactive lever showed a significant effect of session hour $\left(F_{(2,48)}=10.7\right.$, $p<0.001)$ but no effect of drug condition or an interaction between the two factors $(p>0.05$; Fig. $3 E)$. There was no difference in relapse responding for rats with cannula misplacements $(p=0.94 ; n=4$ vehicle, $n=7$ muscimol plus baclofen; Extended Data Fig. 2-2, available at https:// doi.org/10.1523/JNEUROSCI.2693-19.2020. f2-2).

\section{Reacquisition test}

Muscimol plus baclofen injections into the AIV had no effect on reacquisition of fentanyl self-administration (Fig. 3F; Extended Data Fig. 3-1 $B$, available at https:// doi.org/10.1523/JNEUROSCI.2693-19. 2020.f3-1 for individual data). The mixedfactorial ANOVA showed a significant effect of session hour $\left(F_{(5,120)}=7.7, p<\right.$ $0.001)$ but no effect of drug condition $\left(F_{(1,24)}=0.2, p=0.7\right)$ or an interaction between the two factors $\left(F_{(5,120)}=1.2\right.$, $p=0.31$.

Together, AIV inactivation decreased relapse to fentanyl seeking but had no effect on reacquisition to fentanyl selfadministration.
Together, OFC inactivation decreased relapse to fentanyl seeking but had no effect on reacquisition to fentanyl selfadministration.

\section{Exp. 3: Effect of AIV inactivation on relapse to fentanyl seeking after voluntary abstinence}

In exp. 1, we found that relapse after voluntary abstinence was associated with a modest increase in Fos expression in the AIV. The goal of exp. 3 was to determine a causal role of the AIV in this relapse. The timeline of exp. 3 is provided in Figure $3 A$.

\section{Relapse test}

Muscimol plus baclofen injections into the AIV significantly decreased relapse to fentanyl seeking (Fig. 3E, left; Extended Data Fig. 3-1 A, available at https://doi.org/10.1523/JNEUROSCI.269319.2020.f3-1 for individual data). The repeated-measures ANOVA for number of total lever presses included the between-subjects factor of drug condition (vehicle, muscimol plus baclofen) and
Exp. 4: Effect of relapse to fentanyl seeking on Fos expression in afferent projections to OFC

The goal of exp. 4 was to determine which afferent projections to the OFC are activated after relapse to fentanyl seeking, using the retrograde tracer CTb in combination with Fos. The timeline of exp. 4 is provided in Figure $4 A$, and representative CTb injections in the OFC are shown in Figure $4 F$.

\section{Relapse test}

The number of lever presses on the active lever was greater than on the inactive lever during relapse to fentanyl seeking (Fig. 4E; Extended Data Fig. 4-1A, available at https://doi.org/10.1523/ JNEUROSCI.2693-19.2020.f4-1 for individual data). The repeated-measures ANOVA for number of lever presses included the within-subjects factors of session time (30, 60, $90 \mathrm{~min})$ and lever (active, inactive). This analysis showed significant effects of session time $\left(F_{(2,12)}=72.7, p<0.001\right)$ and lever $\left(F_{(1,6)}=71.0\right.$, 
$p<0.001)$ and an interaction between the two factors $\left(F_{(2,12)}=79.1, p<\right.$ $0.001)$.

\section{Fos plus CTb quantification}

Relapse to fentanyl seeking after voluntary abstinence was associated with selective activation of $\mathrm{Pir} \rightarrow \mathrm{OFC}$ projections but not projections from other brain regions to the OFC (Fig. 4G; Extended Data Fig. 4-1 B, available at https://doi.org/10.1523/ JNEUROSCI.2693-19.2020.f4-1 for individual data). For Fos + alone, the mixedfactorial ANOVA for number of Fos + cells $/ \mathrm{mm}^{2}$ in the Pir, BLA, mediodorsal thalamic nucleus (MD), or submedius thalamic nucleus (SM) included the between-subjects factor of test condition (no test, test) and the within-subjects factor of brain region (Pir, BLA, MD, SM). This analysis showed significant effects of test condition $\left(F_{(1,9)}=51.1, p<0.001\right)$, brain region $\left(F_{(3,27)}=34.6, p<0.001\right)$, and an interaction between the two factors $\left(F_{(3,27)}=24.0, p<0.001\right)$. For the analysis of $\mathrm{CTb}$ alone, the mixed-factorial ANOVA showed a significant effect of brain region $\left(F_{(3,27)}=10.5, p<0.001\right)$ and no effect of test condition $\left(F_{(1,9)}=\right.$ $0.49, p=0.50)$ or interaction between the two factors $\left(F_{(3,27)}=0.97, p=0.42\right)$. For Fos plus CTb double labeling, the analysis showed significant effects of test condition $\left(F_{(1,9)}=46.2, p<0.001\right)$, brain region $\left(F_{(3,27)}=16.4, p<0.001\right)$, and an interaction between the two factors $\left(F_{(3,27)}=\right.$ $1.0, p<0.001)$. The significant interaction is due to a selective increase in relapse test-induced double-labeled neurons in the Pir but not the other brain regions.

Together, relapse to fentanyl seeking was associated with increased Fos expression in OFC-projecting Pir neurons.

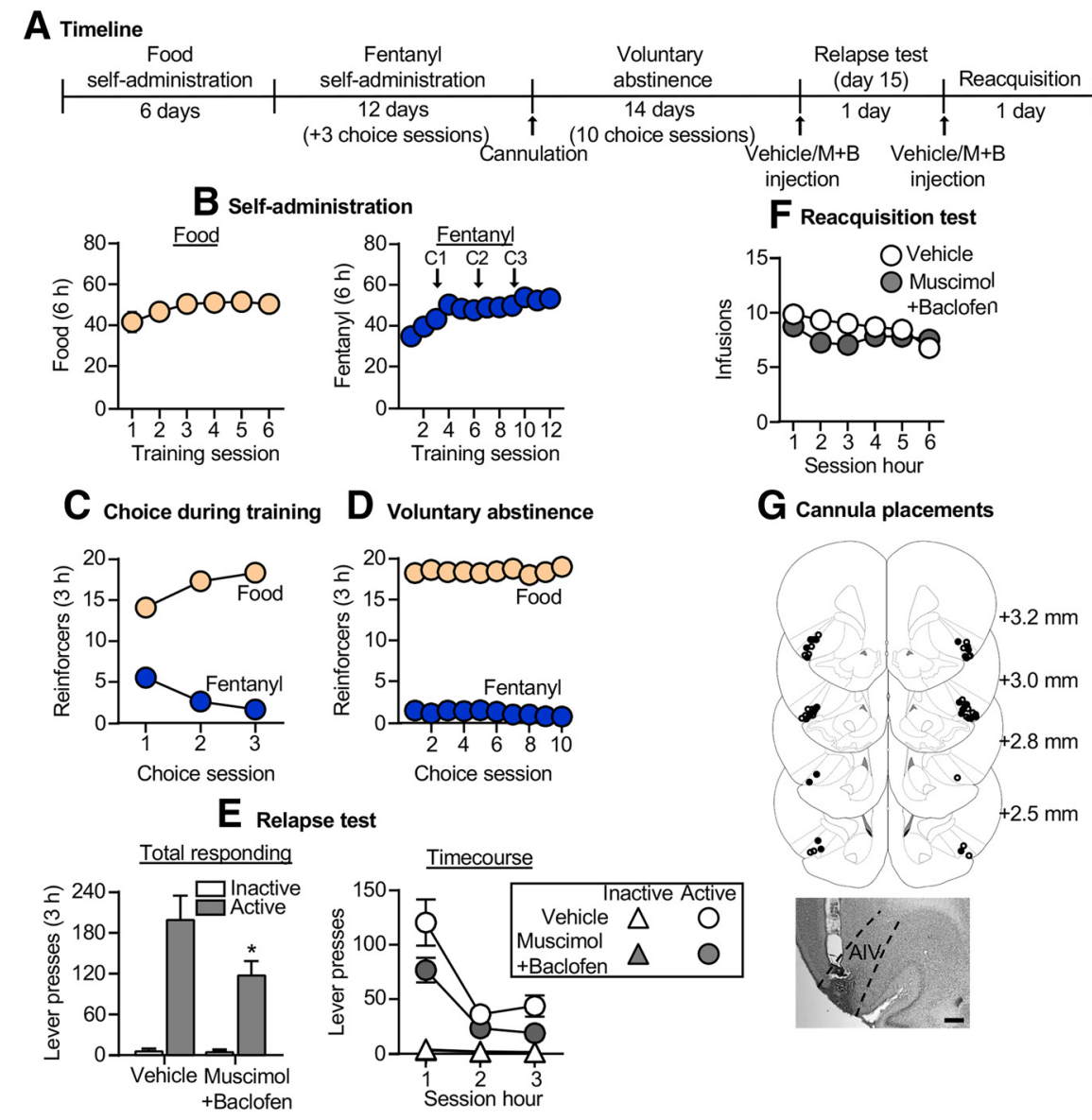

Figure 3. Effect of AIV inactivation on relapse to fentanyl seeking after voluntary abstinence. $\boldsymbol{A}$, Timeline of exp. 3. $\boldsymbol{B}$, Selfadministration: number of reinforced responses (food, 5 pellets/reinforcer; fentanyl, $2.5 \mu \mathrm{g} / \mathrm{kg} / \mathrm{infusion}$ ) during the $6 \mathrm{~h}$ sessions. C, Choice during training: number of food-reinforced responses and fentanyl infusions earned during the $3 \mathrm{~h}$ choice sessions (20 trials/session), denoted by $C_{1}, C_{2}$, and $C 3$ in $\boldsymbol{B}$. D. Voluntary abstinence: number of food-reinforced responses and fentanyl infusions earned during the $3 \mathrm{~h}$ choice sessions (20 trials/session). $\boldsymbol{E}$, Relapse test: number of active and inactive lever presses during the $3 \mathrm{~h}$ test session (left) and $1 \mathrm{~h}$ time course (right) after vehicle or muscimol plus baclofen $(\mathrm{M}+\mathrm{B})$ injections. ${ }^{*} p<0.05$, different from vehicle group. $\boldsymbol{F}$, Reacquisition test: number of fentanyl infusions $(2.5 \mu \mathrm{g} / \mathrm{kg} /$ infusion) during the $1 \mathrm{~h}$ time course of the $6 \mathrm{~h}$ session after vehicle or muscimol plus baclofen injections ( $n=13 / \mathrm{group}$, between-subjects design). Data are the mean \pm SEM. G, Images showing placement of cannula into AIV at $2.5 \times$ magnification. Scale bar, $500 \mu \mathrm{m}$. Vehicle placements are shown with open circles, and muscimol plus baclofen placements are shown with closed circles. For individual data, see Extended Data Figure 3-1, available at https://doi.org/10.1523/JNEUROSCI.2693-19.2020.f3-1. For data from cannula misplacements, see Extended Data Figure 2-2, available at https://doi.org/10.1523/JNEUROSCI.2693-19.2020.f2-2.

\section{Exp. 5: Effect of Pir inactivation on relapse to fentanyl seeking after voluntary abstinence}

In exp. 4, we found that relapse to fentanyl seeking was associated with activation of the Pir and the projections from $\mathrm{Pir} \rightarrow \mathrm{OFC}$. The goal of exp. 5 was to determine whether the Pir plays a causal role in relapse using reversible inactivation (muscimol plus baclofen). The timeline of exp. 5 is provided in Figure $5 A$.

\section{Relapse test}

Muscimol plus baclofen injections into the Pir significantly decreased relapse to fentanyl seeking (Fig. 5E, left; Extended Data Fig. 5-1A, available at https://doi.org/10.1523/JNEUROSCI. 2693-19.2020.f5-1 for individual data). The repeated-measures ANOVA for number of total lever presses included the betweensubjects factor of drug condition and the within-subjects factor of lever. This analysis showed significant effects of drug condition $\left(F_{(1,27)}=5.8, p=0.023\right)$, lever $\left(F_{(1,27)}=81.7, p<0.001\right)$, and a significant interaction between the two factors $\left(F_{(1,27)}=4.9, p=\right.$ $0.036)$. For the time course (Fig. $5 E$, right), the mixed-factorial
ANOVA for number of active lever presses showed significant effects of drug condition $\left(F_{(1,27)}=5.4, p=0.028\right)$ and session hour $\left(F_{(2,54)}=32.3, p<0.001\right)$ but no interaction between the two factors $\left(F_{(2,54)}=1.2, p=0.305\right)$. A similar analysis of inactive lever showed a significant effect of session hour $\left(F_{(2,54)}=9.2, p<\right.$ $0.001)$ but no effect of drug condition or an interaction between the two factors ( $p>0.05$; Fig. $5 E$ ). There was no difference in relapse responding for rats with cannula misplacements in this experiment $(p=0.25 ; n=6$ vehicle, $n=5$ muscimol plus baclofen; Extended Data Fig. 2-2, available at https://doi.org/10. 1523/JNEUROSCI.2693-19.2020.f2-2).

\section{Reacquisition test}

Muscimol plus baclofen injections into the Pir had no effect on reacquisition of fentanyl self-administration (Fig. 5F; Extended Data Fig. 5-1 $B$, available at https://doi.org/10.1523/JNEUROSCI. 2693-19.2020.f5-1 for individual data). The mixed-factorial ANOVA for number of infusions showed significant effects of session hour $\left(F_{(5,135)}=11.2, p<0.001\right)$ and drug condition by 


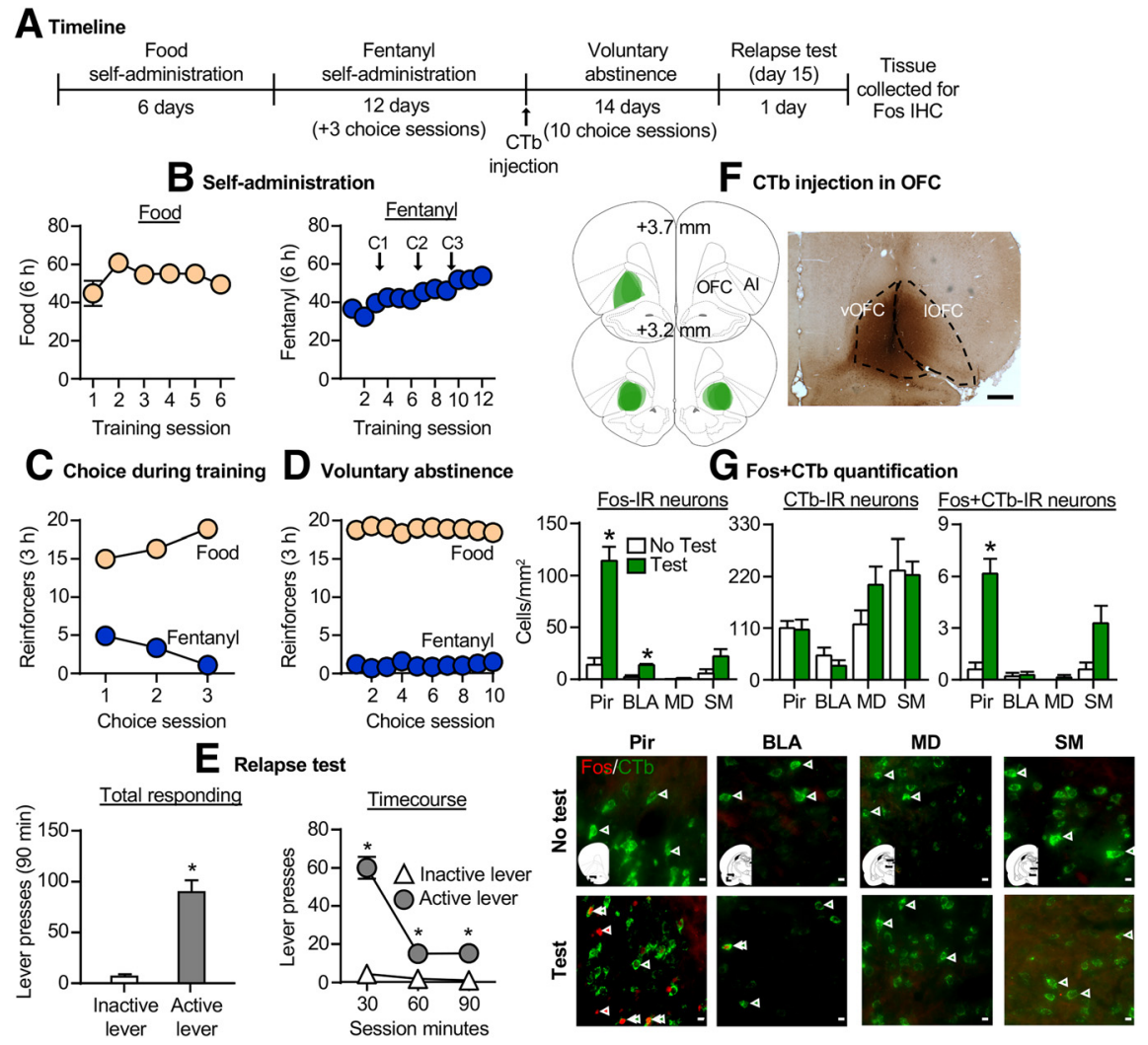

Figure 4. Effect of relapse to fentanyl seeking on Fos expression in afferent projections to the OFC. $\boldsymbol{A}$, Timeline of exp. 4. $\boldsymbol{B}$, Self-administration: number of reinforced responses (food, 5 pellets/reinforcer; fentanyl, $2.5 \mu \mathrm{g} / \mathrm{kg} /$ infusion) during the $6 \mathrm{~h}$ sessions. $\boldsymbol{C}$, Choice during training: number of food-reinforced responses and fentanyl infusions earned during the $3 \mathrm{~h}$ choice sessions (20 trials/session), denoted by C1, C2, and C3 in B. D, Voluntary abstinence: number of food-reinforced responses and fentanyl infusions earned during the $3 \mathrm{~h}$ choice sessions ( 20 trials/session). $\boldsymbol{E}$, Relapse tests: number of active and inactive lever presses during the 90 min test session (left) and the 30 min time course (right). ${ }^{*} p<0.05$, different from inactive lever. $\boldsymbol{F}$, Placement of $\mathrm{CTb}$ injection into the $0 \mathrm{FC}$ and representative image captured at $2.5 \times$ magnification (scale bar, $500 \mu \mathrm{m})$. G, From left to right: number of Fos + cells (counts $/ \mathrm{mm}^{2}$ ) in the Pir, BLA, and thalamus; number of CTb + cells per $\mathrm{mm}^{2}$ in all 4 regions; and number of $\mathrm{CTb}+$ cells that colabel with Fos in all four regions. ${ }^{*} p<0.05$, different from no test group. Representative images showing Fos (red) or CTb (green; $40 \times$ magnification). Scale bar, $100 \mu \mathrm{m}$. Red arrows denote Fos + cell, and green arrows denote $\mathrm{CTb}+$ cell ( $n=5-7 /$ group, between-subjects design). Data are the mean \pm SEM. For individual data, see Extended Data Figure 4-1, available at https://doi.org/10.1523/JNEUROSCI.269319.2020.f4-1.

session hour interaction $\left(F_{(5,135)}=2.8, p=0.02\right)$ but no effect of drug condition $\left(F_{(1,27)}=0.9, p=0.35\right)$. The significant interaction is due to group differences in the third hour of the reacquisition test.

Together, Pir inactivation decreased relapse to fentanyl seeking but had no effect on reacquisition to fentanyl self-administration.

\section{Exp. 6: Effect of anatomical disconnection between Pir and OFC on relapse to fentanyl seeking}

The goal of exp. 6 was to determine whether projections between the Pir and OFC play a causal role in relapse to fentanyl seeking. For this purpose, we used an anatomical disconnection procedure (Setlow et al., 2002). The timeline of exp. 6 is provided in Figure 6 A.

\section{Relapse test}

Muscimol plus baclofen injections into the Pir plus contralateral, but not ipsilateral, OFC significantly decreased the number of active lever presses during relapse to fentanyl seeking (Fig. $6 E$, left; Extended Data Fig. 6-1A, available at https://doi.org/ 10.1523/JNEUROSCI.2693-19.2020.f6-1 for individual data). The repeated-measures ANOVA for number of total lever presses included the between-subjects factor of drug condition (vehicle, muscimol plus baclofen ipsilateral, muscimol plus baclofen contralateral) and the within-subjects factor of lever (inactive, active). This analysis showed significant effects of drug condition $\left(F_{(2,29)}=2.7\right.$, $p=0.046)$ and lever $\left(F_{(1,9)}=100.6, p<\right.$ $0.001)$ but not a significant interaction between drug condition and lever $\left(F_{(2,29)}=\right.$ 2.3, $p=0.117$ ). For the time course (Fig. $6 E$, right), the mixed-factorial ANOVA for number of active lever presses included the between-subjects factor of drug and the within-subjects factor of session hour. This analysis showed a significant effect of session hour $\left(F_{(2,58)}=81.8\right.$, $p=<0.001)$ and a drug condition by session hour interaction $\left(F_{(4,58)}=4.8, p=\right.$ $0.002)$ but no effect of drug condition $\left(F_{(2,29)}=2.74, p=0.081\right)$. The significant interaction is due to group differences in the first hour of the relapse test but not hours 2 and 3. A similar analysis of inactive lever showed a significant effect of drug condition $\left(F_{(2,29)}=4.4, p=0.022\right)$ and session hour $\left(F_{(2,58)}=12.2, p<0.001\right)$ but no interaction between the two factors $(p>$ 0.05; Fig. $6 E$ ). There was no difference in relapse responding for rats with cannula misplacements from this experiment ( $p=0.23 ; n=3$ vehicle, $n=16$ muscimol plus baclofen; Extended Data Fig. 2-2, available at https://doi.org/10.1523/JNEUROSCI. 2693-19.2020.f2-2).

\section{Reacquisition test}

Muscimol plus baclofen injections in the contralateral condition had no effect on reacquisition of fentanyl self-administration (Fig. 6F; Extended Data Fig. 6-1 $B$, available at https://doi.org/10.1523/ JNEUROSCI.2693-19.2020.f6-1 for individual data). The mixed-factorial ANOVA for number of infusions showed no effect of drug condition $\left(F_{(1,8)}\right.$ $=0.1, p=0.815)$, session hour $\left(F_{(5,40)}=0.9, p=0.505\right)$, or an interaction between the two factors $\left(F_{(4,40)}=0.28, p=0.92\right)$.

Together, contralateral disconnection of the Pir and OFC decreased relapse to fentanyl seeking but had no effect on reacquisition of fentanyl self-administration.

\section{Discussion}

We determined whether food choice-induced voluntary abstinence from heroin generalizes to the synthetic opioid fentanyl and investigated circuits of relapse to fentanyl seeking after voluntary abstinence. In agreement with our previous heroin study (Venniro et al., 2017b), there were no sex differences in fentanyl self-administration, the strong preference for palatable food, or relapse to fentanyl seeking. Relapse to fentanyl seeking was associated with a large increase in Fos expression in the OFC and a modest increase in Fos expression in the AIV, and reversible inactivation of these regions decreased relapse. Most importantly, relapse to fentanyl seeking was associated with increased Fos expression in the Pir and in OFC-projecting Pir neurons, and reversible inactivation of the Pir or projections between the Pir and 
OFC decreased relapse. Finally, inactivation of the OFC, AIV, Pir, and Pir-OFC disconnection had no effect on reacquisition, suggesting dissociable brain mechanisms for reinforced opioid taking and nonreinforced opioid seeking (Bossert et al., 2013; Reiner et al., 2019).

\section{Food choice-induced voluntary abstinence}

We observed a strong preference for palatable food over fentanyl, in agreement with our previous studies with heroin and methamphetamine (Caprioli et al., 2015; Venniro et al., 2017b) and previous reports of strong preference for saccharin over heroin (Lenoir et al., 2013; Madsen and Ahmed, 2015). However, Townsend et al. (2019) reported increased fentanyl preference over liquid Ensure. These discrepant findings are likely due to different experimental parameters, including session duration, fentanyl dose $(2.5 \mu \mathrm{g} / \mathrm{kg} /$ infusion in our study vs $0.32-10 \mu \mathrm{g} / \mathrm{kg} /$ infusion in the Townsend et al. study) and food type (high-carbohydrate pellets in our study vs diluted Ensure in the Townsend et al. study).

\section{Role of OFC and AIV in relapse to drug seeking}

We found that relapse to fentanyl seeking was associated with increased Fos expression in the OFC, and that reversible inactivation of the lOFC decreased relapse after voluntary abstinence. These data agree with a previous study showing that muscimol plus baclofen or Daun02 inactivation of Fos-expressing neurons in the OFC decreases heroin seeking after forced abstinence (Fanous et al., 2012). Thus, OFC activity appears critical for relapse to opioid seeking, independent of the opioid or abstinence procedure. Other studies reported that inhibition of OFC activity decreases cue-induced and context-induced reinstatement of cocaine seeking after extinction (Fuchs et al., 2004; Lasseter et al., 2009, 2011). However, in our recent methamphetamine studies, we found that OFC inactivation has no effect on relapse after either forced or food choiceinduced abstinence (Li et al., 2015a; Venniro et al., 2017a). Together, the present and previous results indicate a role of the OFC in relapse to opioid and cocaine seeking, but surprisingly, not methamphetamine seeking.

Previous studies primarily examined the role of the lOFC in drug seeking, but two studies showed that inactivation of the vOFC or medial OFC has no effect on heroin seeking after forced abstinence or cocaine cue-induced reinstatement to cocaine seeking after extinction (Fuchs et al., 2004; Fanous et al., 2012). However, the role of OFC subregions in a given reinforcerrelated behavior may be more nuanced (Izquierdo, 2017). Indeed, Malvaez et al. (2019) reported that lOFC and medial OFC projections to the BLA play different roles in encoding the positive value of a reinforcer and retrieving this value from memory.
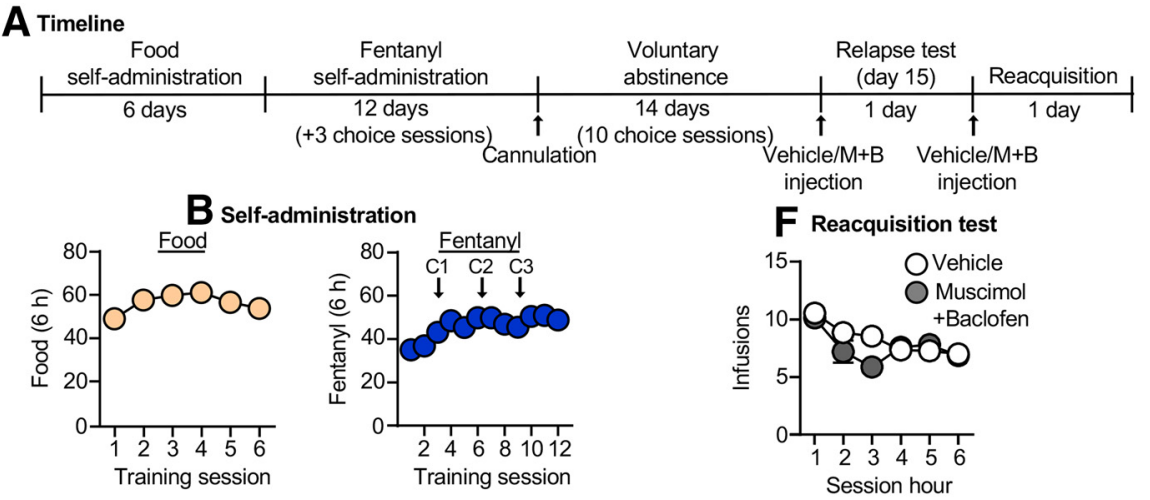

D voluntary abstinence
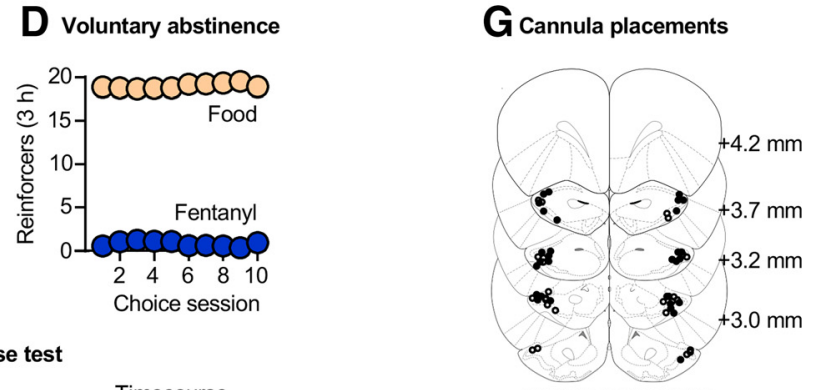

Relapse test
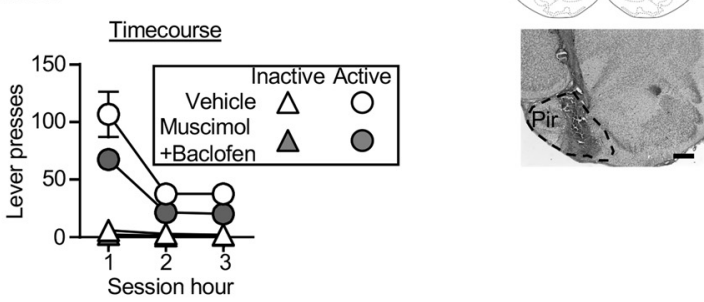

Figure 5. Effect of Pir inactivation on relapse to fentanyl seeking after voluntary abstinence. $\boldsymbol{A}$, Timeline of exp. 5. $\boldsymbol{B}$, Selfadministration: number of reinforced responses (food, 5 pellets/reinforcer; fentanyl, $2.5 \mu \mathrm{g} / \mathrm{kg} / \mathrm{infusion}$ ) during the $6 \mathrm{~h}$ sessions. Choice during training: number of food-reinforced responses and fentanyl infusions earned during the $3 \mathrm{~h}$ choice sessions (20

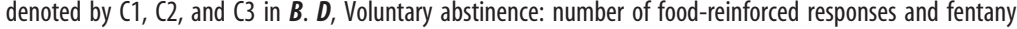
(he $3 \mathrm{~h}$ choice sessions ( 20 trials/session). $\boldsymbol{E}$, Relapse test: number of active and inactive lever presses 作 the $6 \mathrm{~h}$ session after vehicle or muscimol plus baclofen injections ( $n=14-15 /$ group, between-subjects design). Data are the are shown with open circles, and muscimol plus baclofen placements are shown with closed circles. For individual data, see Extended Data Figure 5-1, available at https://doi.org/10.1523/JNEUROSCI.2693-19.2020.f5-1. For data from cannula misplacements, see Extended Data Figure 2-2, available at https://doi.org/10.1523/JNEUROSCI.2693-19.2020.f2-2.

Although our data suggest that both lOFC and vOFC subregions are critical for relapse to fentanyl seeking, we did not observe a statistically significant effect for vOFC inactivation $(p=0.078)$. This is likely due to one high responder in the vOFC muscimol plus baclofen condition (326 lever presses during testing; Extended Data Fig. 2-1A, available at https://doi.org/10.1523/ JNEUROSCI.2693-19.2020.f2-1) that did not meet our outlier exclusion criterion (3 SDs above the group mean).

We also found that relapse to fentanyl seeking was associated with increased Fos expression in the AIV, and that AIV inactivation decreased relapse. These results extend our previous results on AIV role in relapse to methamphetamine seeking after food choice-induced abstinence (Venniro et al., 2017a). Inactivation of anterior insular cortex decreases cue-induced reinstatement of cocaine and nicotine seeking and context-induced reinstatement of cocaine seeking (Cosme et al., 2015; Pushparaj et al., 2015; Rotge et al., 2017). Together, these results identify an important role of this brain region in relapse to drug seeking across drug classes and relapse models. 


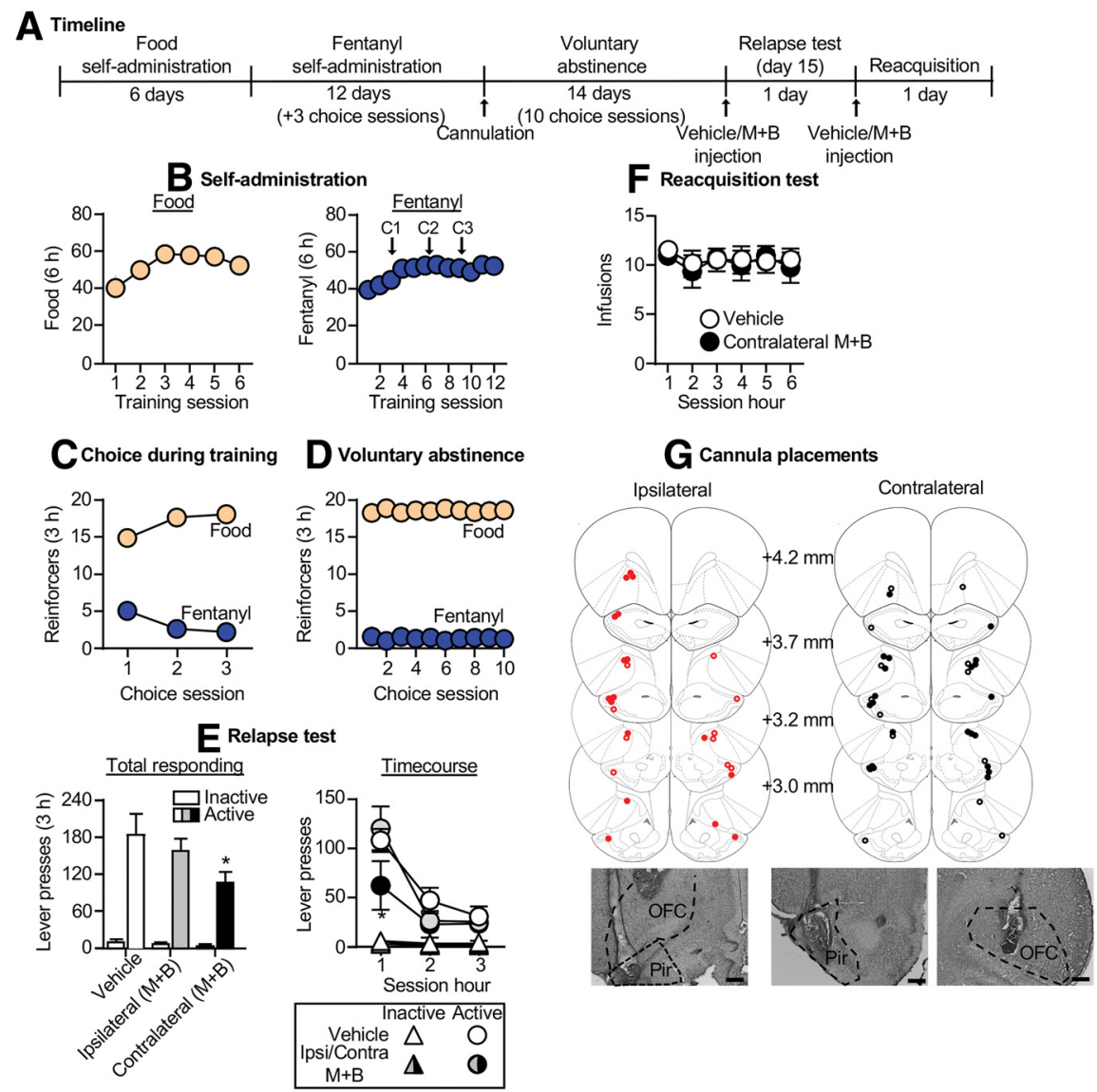

Figure 6. Effect of anatomical disconnection between the Pir and OFC on relapse to fentanyl seeking. $A$, Timeline of exp. 6. $\boldsymbol{B}$, Self-administration: number of reinforced responses (food, 5 pellets/reinforcer; fentanyl, $2.5 \mu \mathrm{g} / \mathrm{kg} /$ infusion) during the $6 \mathrm{~h}$ sessions. $C$, Choice during training: number of food-reinforced responses and fentanyl infusions earned during the $3 \mathrm{~h}$ choice sessions ( 20 trials/session), denoted by $\mathrm{C}, \mathrm{C}$, and $\mathrm{C}$ in $\boldsymbol{B}$. D. Voluntary abstinence: number of food-reinforced responses and fentanyl infusions earned during the $3 \mathrm{~h}$ choice sessions ( 20 trials/session). $\boldsymbol{E}$, Relapse test: number of active and inactive lever presses during the $3 \mathrm{~h}$ test session (left) and $1 \mathrm{~h}$ time course (right) after unilateral Pir and ipsilateral or contralateral $\mathrm{OFC}$ vehicle or muscimol plus baclofen $(\mathrm{M}+\mathrm{B})$ injections. ${ }^{*} p<0.05$, different from vehicle and ipsilateral groups ( $n=9-12 /$ group, between-subjects design). $\boldsymbol{F}$, Reacquisition test: number of fentanyl infusions $(2.5 \mu \mathrm{g} / \mathrm{kg} /$ infusion) during the $1 \mathrm{~h}$ time course of the $6 \mathrm{~h}$ session after unilateral Pir and contralateral OFC vehicle or muscimol plus baclofen injections ( $n=5 /$ group, between-subjects design). Data are the mean \pm SEM. $G$, Images showing placement of cannulas in the $\mathrm{OFC}$ and Pir at $2.5 \times$ magnification. Scale bar, $500 \mu \mathrm{m}$. Placements in the ipsilateral condition are shown in red, and placements in the contralateral condition are shown in black. Vehicle placements are shown with open circles, and muscimol plus baclofen placements are shown with closed circles. For individual data, see Extended Data Figure 6-1, available at https://doi.org/10.1523/JNEUROSCI.2693-19.2020.f6-1. For data from cannula misplacements, see Extended Data Figure 2-2, available at https://doi.org/10.1523/JNEUROSCI.2693-19.2020.f2-2.

\section{Role of Pir and projections between Pir and OFC in relapse to fentanyl seeking after voluntary abstinence}

To determine relapse-associated, projection-specific activation of OFC afferents, we combined the retrograde tracer CTb with the activity marker Fos. We analyzed major projection targets of OFC: Pir, BLA, and thalamic nuclei [mediodorsal nucleus and submedius nucleus (Chen et al., 2014; Murphy and Deutch, 2018)]. Surprisingly, we found that relapse to fentanyl seeking was associated with a selective increase in Fos-expressing neurons projecting from the ipsilateral Pir to the OFC. Consistent with a prior anatomical study (Murphy and Deutch, 2018), we did not observe CTb labeling in Pir contralateral to the OFC injection site (Extended Data Fig. 4-1C, available at https://doi.org/10.1523/ JNEUROSCI.2693-19.2020.f4-1). Consistent with prior studies (Chen et al., 2014; Murphy and Deutch, 2018), we found more $\mathrm{CTb}+$ neurons in anterior portions of the Pir at the level of the OFC (4.2-2.8 $\mathrm{mm}$ anterior to bregma) compared with posterior sections (data not shown). We also found a small proportion of Fos + Pir neurons were colabeled with $\mathrm{CTb}(\sim 5 \%)$. This small proportion of activated neurons is consistent with the neuronal ensemble hypothesis, which posits that a small percentage of neurons control a given learned behavior (Hebb, 1949). Indeed, studies using the Daun02 inactivation procedure (Cruz et al., 2013) have shown that inhibition of a small proportion of relapseassociated Fos + neurons in different brain areas decreases relapse to drug seeking (Bossert et al., 2011; Caprioli et al., 2017; Warren et al., 2019).

In follow-up experiments, we found that Pir inactivation and unilateral Pir inactivation plus unilateral OFC inactivation in the contralateral, but not ipsilateral, hemisphere decreased relapse to fentanyl seeking. Given our data showing increased Fos expression in OFC-projecting Pir neurons, and that $\mathrm{Pir} \rightarrow \mathrm{OFC}$ projections are ipsilateral, we interpret these data to suggest that $\mathrm{Pir} \rightarrow$ OFC projections contribute to relapse to fentanyl seeking. The Pir is an olfaction region and an extension of the olfactory cortex (Stettler and Axel, 2009). The role of the Pir in the behavioral effects of drugs is largely unknown, and the published papers are limited to correlational results. Cue-induced reinstatement of alcohol seeking is associated with increased phosphorylated calmodulin-dependent protein kinase II in the Pir (Salling et al., 2017). Cocaine conditioned place preference is associated with increased Fos expression in the Pir (Crawford et al., 1995), and withdrawal from experimenterinjected cocaine is associated with increased oxytocin receptor binding in the Pir (Georgiou et al., 2016).

Finally, our results on the role of the Pir in conditioned drug effects and motivated behavior extend previous studies on the role of the Pir in conditioned odor or flavor preference and the social transmission of food preference. Ross and Eichenbaum (2006) reported that memory retrieval of social transmission of food preference is associated with increased Fos expression in the Pir (and OFC). Loureiro et al. (2019) showed a critical role of a Pir to prefrontal cortex projections in this behavior. Acquisition of conditioned flavor preference is associated with increased Fos expression in the Pir (Mediavilla et al., 2016), and lesions or antagonists of NMDA or cannabinoid type 1 receptors decrease conditioned flavor preference (Mediavilla et al., 2016; Mukherjee and Yuan, 2016; Terral et al., 2019).

\section{Methodological considerations}

One methodological issue is that intracranial muscimol plus baclofen injections may cause nonspecific motor deficits. This is unlikely because, in all experiments, muscimol plus baclofen inactivation had no effect on reacquisition of fentanyl self- 
administration. We cannot rule out the possibility of diffusion of intracranial muscimol plus baclofen injections into nearby regions (Wise and Hoffman, 1992). Specifically, lOFC/vOFC injections may have diffused into the adjacent OFC subregion or the AIV or Pir, or AIV or Pir injections diffused into the OFC. Importantly, we limited our analysis to only include rats with Pir injections ventral to the rhinal fissure, which separates the OFC and Pir along the dorsal/ventral axis. Additionally, there was no significant effect of muscimol plus baclofen injections in rats with cannula misplacements (Extended Data Fig. 2-2, available at https://doi.org/10.1523/JNEUROSCI.2693-19.2020.f2-2). Thus, although a diffusion-related alternative interpretation of our data cannot be completely ruled out, based on the projection-specific activation data and the disconnection findings, a likely interpretation of our findings is that activity of the Pir and Pir $\rightarrow$ OFC projections contribute to relapse to fentanyl seeking after food choice-induced voluntary abstinence.

Another interpretation issue to consider is that one cannot infer directionality of a pathway from disconnection experiments. Thus, because the Pir and OFC are reciprocally connected (Illig, 2005), we cannot rule out the possibility that OFC $\rightarrow$ Pir projections contribute to relapse to fentanyl seeking. Finally, our data indicate that other brain regions contribute to relapse to fentanyl seeking, because our manipulations decreased active lever pressing by only $\sim 40 \%$.

\section{Conclusions}

We combined reversible pharmacological inactivation, retrograde tracing and Fos immunohistochemistry, and an anatomical disconnection procedure to demonstrate that activation of the OFC, AIV, Pir, and Pir-OFC projections contribute to relapse to fentanyl seeking after food choice-induced voluntary abstinence. Our results extend previous studies on the role of the OFC and AIV in relapse to drug seeking (Bossert et al., 2013; Reiner et al., 2019 ) and identify a novel role of the Pir and Pir $\rightarrow$ OFC projections in relapse after voluntary abstinence.

\section{References}

Ahmed SH, Guillem K, Vandaele Y (2013) Sugar addiction: pushing the drug-sugar analogy to the limit. Curr Opin Clin Nutr Metab Care 16:434439.

Arguello AA, Richardson BD, Hall JL, Wang R, Hodges MA, Mitchell MP, Stuber GD, Rossi DJ, Fuchs RA (2017) Role of a lateral orbital frontal cortex-basolateral amygdala circuit in cue-induced cocaine-seeking behavior. Neuropsychopharmacology 42:727-735.

Bossert JM, Stern AL, Theberge FR, Cifani C, Koya E, Hope BT, Shaham Y (2011) Ventral medial prefrontal cortex neuronal ensembles mediate context-induced relapse to heroin. Nat Neurosci 14:420-422.

Bossert JM, Marchant NJ, Calu DJ, Shaham Y (2013) The reinstatement model of drug relapse: recent neurobiological findings, emerging research topics, and translational research. Psychopharmacology 229:453-476.

Calu DJ, Chen YW, Kawa AB, Nair SG, Shaham Y (2014) The use of the reinstatement model to study relapse to palatable food seeking during dieting. Neuropharmacology 76:395-406.

Caprioli D, Venniro M, Zeric T, Li X, Adhikary S, Madangopal R, Marchant NJ, Lucantonio F, Schoenbaum G, Bossert JM, Shaham Y (2015) Effect of the novel positive allosteric modulator of metabotropic glutamate receptor 2 AZD8529 on incubation of methamphetamine craving after prolonged voluntary abstinence in a rat model. Biol Psychiatry 78:463-473.

Caprioli D, Venniro M, Zhang M, Bossert JM, Warren BL, Hope BT, Shaham Y (2017) Role of dorsomedial striatum neuronal ensembles in incubation of methamphetamine craving after voluntary abstinence. J Neurosci 37:1014-1027.

Chen CF, Zou DJ, Altomare CG, Xu L, Greer CA, Firestein SJ (2014) Nonsensory target-dependent organization of piriform cortex. Proc Natl Acad Sci U S A 111:16931-16936.

Cifani C, Koya E, Navarre BM, Calu DJ, Baumann MH, Marchant NJ, Liu QR,
Khuc T, Pickel J, Lupica CR, Shaham Y, Hope BT (2012) Medial prefrontal cortex neuronal activation and synaptic alterations after stressinduced reinstatement of palatable sood seeking: a study using c-fos-GFP transgenic female rats. J Neurosci 32:8480-8490.

Cosme CV, Gutman AL, LaLumiere RT (2015) The dorsal agranular insular cortex regulates the cued reinstatement of cocaine-seeking, but not foodseeking, behavior in rats. Neuropsychopharmacology 40:2425-2433.

Crawford CA, McDougall SA, Bolanos CA, Hall S, Berger SP (1995) The effects of the kappa agonist U-50,488 on cocaine-induced conditioned and unconditioned behaviors and fos immunoreactivity. Psychopharmacology (Berl) 120:392-399.

Cruz FC, Koya E, Guez-Barber DH, Bossert JM, Lupica CR, Shaham Y, Hope BT (2013) New technologies for examining the role of neuronal ensembles in drug addiction and fear. Nat Rev Neurosci 14:743-754.

Edelstein AD, Tsuchida MA, Amodaj N, Pinkard H, Vale FD, Stuurman N (2014) Advanced methods of microscope control using $\mu$ Manager software. Journal of Biological Methods 2014 1:e11.

Epstein DH, Preston KL (2003) The reinstatement model and relapse prevention: a clinical perspective. Psychopharmacology 168:31-41.

Fanous S, Goldart EM, Theberge FR, Bossert JM, Shaham Y, Hope BT (2012) Role of orbitofrontal cortex neuronal ensembles in the expression of incubation of heroin craving. J Neurosci 32:11600-11609.

Fuchs RA, Evans KA, Parker MP, See RE (2004) Differential involvement of orbitofrontal cortex subregions in conditioned cue-induced and cocaineprimed reinstatement of cocaine seeking in rats. J Neurosci 24:66006610

Gaffan D, Murray EA, Fabre-Thorpe M (1993) Interaction of the amygdala with the frontal lobe in reward memory. Eur J Neurosci 5:968-975.

Georgiou P, Zanos P, Hourani S, Kitchen I, Bailey A (2016) Cocaine abstinence induces emotional impairment and brain region-specific upregulation of the oxytocin receptor binding. Eur J Neurosci 44:2446-2454.

Guillem K, Ahmed SH (2018) Preference for cocaine is represented in the orbitofrontal cortex by an increased proportion of cocaine use-coding neurons. Cereb Cortex 28:819-832.

Guillem K, Brenot V, Durand A, Ahmed SH (2018) Neuronal representation of individual heroin choices in the orbitofrontal cortex. Addict Biol 23:880-888.

Hebb DO (1949) The organization of behavior. New York: Wiley.

Hunt WA, Barnett LW, Branch LG (1971) Relapse rates in addiction programs. J Clin Psychol 27:455-456.

Illig KR (2005) Projections from orbitofrontal cortex to anterior piriform cortex in the rat suggest a role in olfactory information processing. J Comp Neurol 488:224-231.

Izquierdo A (2017) Functional heterogeneity within rat orbitofrontal cortex in reward learning and decision making. J Neurosci 37:10529-10540.

Jaffe JH (1990) Drug addiction and drug abuse. In: Goodman and Gilman's the pharmacological basis of therapeutics (Gilman AG, Rall TW, Nies AS, Taylor P, eds) pp 522-573. New York: Pergamon.

Jentsch JD, Olausson P, De La Garza R 2nd, Taylor JR (2002) Impairments of reversal learning and response perseveration after repeated, intermittent cocaine administrations to monkeys. Neuropsychopharmacology 26 : 183-190.

Kalivas PW, McFarland K (2003) Brain circuitry and the reinstatement of cocaine-seeking behavior. Psychopharmacology 168:44-56.

Katz JL, Higgins ST (2003) The validity of the reinstatement model of craving and relapse to drug use. Psychopharmacology 168:21-30.

Koya E, Spijker S, Voorn P, Binnekade R, Schmidt ED, Schoffelmeer AN, De Vries TJ, Smit AB (2006) Enhanced cortical and accumbal molecular reactivity associated with conditioned heroin, but not sucrose-seeking behaviour. J Neurochem 98:905-915.

Kuntz KL, Patel KM, Grigson PS, Freeman WM, Vrana KE (2008) Heroin self-administration: II. CNS gene expression following withdrawal and cue-induced drug-seeking behavior. Pharmacol Biochem Behav 90:349 356.

Langleben DD, Ruparel K, Elman I, Busch-Winokur S, Pratiwadi R, Loughead J, O'Brien CP, Childress AR (2008) Acute effect of methadone maintenance dose on brain FMRI response to heroin-related cues. Am J Psychiatry 165:390-394.

Lasseter HC, Ramirez DR, Xie X, Fuchs RA (2009) Involvement of the lateral orbitofrontal cortex in drug context-induced reinstatement of cocaine-seeking behavior in rats. Eur J Neurosci 30:1370-1381.

Lasseter HC, Wells AM, Xie X, Fuchs RA (2011) Interaction of the basolateral 
amygdala and orbitofrontal cortex is critical for drug context-induced reinstatement of cocaine-seeking behavior in rats. Neuropsychopharmacology $36: 711-720$

Lasseter HC, Xie X, Arguello AA, Wells AM, Hodges MA, Fuchs RA (2014) Contribution of a mesocorticolimbic subcircuit to drug context-induced reinstatement of cocaine-seeking behavior in rats. Neuropsychopharmacology 39:660-669.

Lenoir M, Cantin L, Vanhille N, Serre F, Ahmed SH (2013) Extended heroin access increases heroin choices over a potent nondrug alternative. Neuropsychopharmacology 38:1209-1220.

Li X, Rubio FJ, Zeric T, Bossert JM, Kambhampati S, Cates HM, Kennedy PJ, Liu QR, Cimbro R, Hope BT, Nestler EJ, Shaham Y (2015a) Incubation of methamphetamine craving is associated with selective increases in expression of bdnf and trkb, glutamate receptors, and epigenetic enzymes in cue-activated fos-expressing dorsal striatal neurons. J Neurosci 35: $8232-8244$.

Li X, Zeric T, Kambhampati S, Bossert JM, Shaham Y (2015b) The central amygdala nucleus is critical for incubation of methamphetamine craving. Neuropsychopharmacology 40:1297-1306.

Loureiro M, Achargui R, Flakowski J, Van Zessen R, Stefanelli T, Pascoli V, Lüscher C (2019) Social transmission of food safety depends on synaptic plasticity in the prefrontal cortex. Science 364:991-995.

Lucantonio F, Stalnaker TA, Shaham Y, Niv Y, Schoenbaum G (2012) The impact of orbitofrontal dysfunction on cocaine addiction. Nat Neurosci 15:358-366.

Lucantonio F, Kambhampati S, Haney RZ, Atalayer D, Rowland NE, Shaham Y, Schoenbaum G (2015) Effects of prior cocaine versus morphine or heroin self-administration on extinction learning driven by overexpectation versus omission of reward. Biol Psychiatry 77:912-920.

Luppi PH, Fort P, Jouvet M (1990) Iontophoretic application of unconjugated cholera toxin $\mathrm{B}$ subunit ( $\mathrm{CTb}$ ) combined with immunohistochemistry of neurochemical substances: a method for transmitter identification of retrogradely labeled neurons. Brain Res 534:209-224.

Madsen HB, Ahmed SH (2015) Drug versus sweet reward: greater attraction to and preference for sweet versus drug cues. Addict Biol 20:433-444.

Mahler SV, Aston-Jones GS (2012) Fos activation of selective afferents to ventral tegmental area during cue-induced reinstatement of cocaine seeking in rats. J Neurosci 32:13309-13326.

Malvaez M, Shieh C, Murphy MD, Greenfield VY, Wassum KM (2019) Distinct cortical-amygdala projections drive reward value encoding and retrieval. Nat Neurosci 22:762-769.

Marchant NJ, Hamlin AS, McNally GP (2009) Lateral hypothalamus is required for context-induced reinstatement of extinguished reward seeking. J Neurosci 29:1331-1342.

Marchant NJ, Rabei R, Kaganovsky K, Caprioli D, Bossert JM, Bonci A, Shaham Y (2014) A critical role of lateral hypothalamus in context-induced relapse to alcohol seeking after punishment-imposed abstinence. J Neurosci 34:7447-7457.

Marchant NJ, Campbell EJ, Whitaker LR, Harvey BK, Kaganovsky K, Adhikary S, Hope BT, Heins RC, Prisinzano TE, Vardy E, Bonci A, Bossert JM, Shaham Y (2016) Role of ventral subiculum in context-induced relapse to alcohol seeking after punishment-imposed abstinence. J Neurosci 36:3281-3294.

McFarland K, Kalivas PW (2001) The circuitry mediating cocaine-induced reinstatement of drug-seeking behavior. J Neurosci 21:8655-8663.

Mediavilla C, Martin-Signes M, Risco S (2016) Role of anterior piriform cortex in the acquisition of conditioned flavour preference. Sci Rep 6:33365.

Morgan JI, Curran T (1991) Stimulus-transcription coupling in the nervous system: involvement of the inducible proto-oncogenes fos and jun. Annu Rev Neurosci 14:421-451.

Mukherjee B, Yuan Q (2016) NMDA receptors in mouse anterior piriform cortex initialize early odor preference learning and L-type calcium channels engage for long-term memory. Sci Rep 6:35256.

Murphy MJM, Deutch AY (2018) Organization of afferents to the orbitofrontal cortex in the rat. J Comp Neurol 526:1498-1526.

Pelloux Y, Minier-Toribio A, Hoots JK, Bossert JM, Shaham Y (2018) Opposite effects of basolateral amygdala inactivation on context-induced relapse to cocaine seeking after extinction versus punishment. J Neurosci 38:51-59.

Pickens CL, Cifani C, Navarre BM, Eichenbaum H, Theberge FR, Baumann
MH, Calu DJ, Shaham Y (2012) Effect of fenfluramine on reinstatement of food seeking in female and male rats: implications for the predictive validity of the reinstatement model. Psychopharmacology 221:341-353.

Pushparaj A, Kim AS, Musiol M, Trigo JM, Le Foll B (2015) Involvement of the rostral agranular insular cortex in nicotine self-administration in rats. Behav Brain Res 290:77-83.

Reiner DJ, Fredriksson I, Lofaro OM, Bossert JM, Shaham Y (2019) Relapse to opioid seeking in rat models: behavior, pharmacology and circuits. Neuropsychopharmacology 44:465-477.

Ross RS, Eichenbaum H (2006) Dynamics of hippocampal and cortical activation during consolidation of a nonspatial memory. J Neurosci 26 : 4852-4859.

Rossi LM, Reverte I, Ragozzino D, Badiani A, Venniro M, Caprioli D (2020) Role of nucleus accumbens core but not shell in incubation of methamphetamine craving after voluntary abstinence. Neuropsychopharmacology 45:256-265.

Rotge JY, Cocker PJ, Daniel ML, Belin-Rauscent A, Everitt BJ, Belin D (2017) Bidirectional regulation over the development and expression of loss of control over cocaine intake by the anterior insula. Psychopharmacology (Berl) 234:1623-1631.

Salling MC, Hodge CJ, Psilos KE, Eastman VR, Faccidomo SP, Hodge CW (2017) Cue-induced reinstatement of alcohol-seeking behavior is associated with increased CaMKII T286 phosphorylation in the reward pathway of mice. Pharmacol Biochem Behav 163:20-29.

Sell LA, Morris JS, Bearn J, Frackowiak RS, Friston KJ, Dolan RJ (2000) Neural responses associated with cue evoked emotional states and heroin in opiate addicts. Drug Alcohol Depend 60:207-216.

Setlow B, Holland PC, Gallagher M (2002) Disconnection of the basolateral amygdala complex and nucleus accumbens impairs appetitive pavlovian second-order conditioned responses. Behav Neurosci 116:267-275.

Shalev U, Grimm JW, Shaham Y (2002) Neurobiology of relapse to heroin and cocaine seeking: a review. Pharmacol Rev 54:1-42.

Sinha R (2011) New findings on biological factors predicting addiction relapse vulnerability. Curr Psychiatry Rep 13:398-405.

Stettler DD, Axel R (2009) Representations of odor in the piriform cortex. Neuron 63:854-864.

Stopper CM, Floresco SB (2014) What's better for me? Fundamental role for lateral habenula in promoting subjective decision biases. Nat Neurosci 17:33-35.

Terral G, Busquets-Garcia A, Varilh M, Achicallende S, Cannich A, Bellocchio L, Bonilla-Del Río I, Massa F, Puente N, Soria-Gomez E, Grandes P, Ferreira G, Marsicano G (2019) CB1 Receptors in the anterior piriform cortex control odor preference memory. Curr Biol 29:2455-2464.e5.

Torregrossa MM, Quinn JJ, Taylor JR (2008) Impulsivity, compulsivity, and habit: the role of orbitofrontal cortex revisited. Biol Psychiatry 63: 253-255.

Townsend EA, Negus SS, Caine SB, Thomsen M, Banks ML (2019) Sex differences in opioid reinforcement under a fentanyl vs. food choice procedure in rats. Neuropsychopharmacology 44:2022-2029.

Venniro M, Caprioli D, Shaham Y (2016) Animal models of drug relapse and craving: from drug priming-induced reinstatement to incubation of craving after voluntary abstinence. Prog Brain Res 224:25-52.

Venniro M, Caprioli D, Zhang M, Whitaker LR, Zhang S, Warren BL, Cifani C, Marchant NJ, Yizhar O, Bossert JM, Chiamulera C, Morales M, Shaham Y (2017a) The anterior insular cortex->central amygdala glutamatergic pathway is critical to relapse after contingency management. Neuron 96:414-427.e8.

Venniro M, Zhang M, Shaham Y, Caprioli D (2017b) Incubation of methamphetamine but not heroin craving after voluntary abstinence in male and female rats. Neuropsychopharmacology 42:1126-1135.

Wade CL, Vendruscolo LF, Schlosburg JE, Hernandez DO, Koob GF (2015) Compulsive-like responding for opioid analgesics in rats with extended access. Neuropsychopharmacology 40:421-428.

Warren BL, Kane L, Venniro M, Selvam P, Quintana-Feliciano R, Mendoza MP, Madangopal R, Komer L, Whitaker LR, Rubio FJ, Bossert JM, Caprioli D, Shaham Y, Hope BT (2019) Separate vmPFC ensembles control cocaine self-administration versus extinction in rats. J Neurosci 39:7394-7407.

Wise RA, Hoffman DC (1992) Localization of drug reward mechanisms by intracranial injections. Synapse 10:247-263. 